\title{
Presence and fate of microplastics in the water sources: focus on the role of wastewater and drinking water treatment plants
}

\author{
Margherita Barchiesi *, Agostina Chiavola, Camilla Di Marcantonio, Maria Rosaria Boni \\ DICEA, Department of Civil, Constructional and Environmental Engineering, Faculty of Civil and Industrial Engineering, University of Rome Sapienza, Via Eudossiana 18, \\ 00184 Rome, Italy
}

\section{A R T I C L E I N F O}

\section{Keywords:}

Drinking Water treatment plants

Microplastics

Wastewater treatment plants

Water

\begin{abstract}
A B S T R A C T
Microplastics are nowadays considered as ubiquitous pollutants since have been found widespread in all environmental compartments, particularly in the water sources. In the urban water cycle, the drinking water treatment plants and the wastewater treatment plants are the first and last barriers to microplastics pollution, respectively. The present work aims at presenting the information available on microplastic presence in the urban water cycle, reporting and linking what is known at the different stages. Focus is on the water sources and on the role of the water treatment plants as source and control of microplastics pollution. Aspects evaluated are microplastics abundance, characterization in terms of morphology, size and polymer composition, spatial and temporal variations, factors influencing their distribution and abundance, effects of treatments on their removal.

Up to now there is no common framework for microplastics collection, sample pre-treatment, identification, quantification and classification. Data comparison is hindered due to the various analytical protocols implemented; hence the conclusions driven are mostly indicative or of very local significance. The available information is not evenly distributed among the urban water cycle components. For the establishment of proper microplastics pollution control strategies, the relative role of wastewater and drinking water treatment plants needs to be better deepened in terms of both quantity and quality effects.

All these aspects are afforded in the present review which is based on the more recent data published by the specialized literature.
\end{abstract}

\section{Introduction}

Plastic is a general term introduced to gather materials made of synthetic polymers. Such various polymers are origin to materials that vary widely in terms of physical and chemical characteristics. Hence the versatility of plastic and its subsequent widespread use: from clothes to everyday life tools, from personal care products to transport means and many others. Plastic production rocketed over the years since the beginning of its mass distribution. Drawback of this large diffusion is that $60 \%$ of all the plastic produced has been discharged into landfills or ended up in natural environments [1,2]. The high persistence results in a worldwide spreading of plastic litter due to various transport processes. Their spread is also favored by the fragmentation of plastic debris into smaller pieces, reaching the size of micro and nanometers [3]. Therefore, Microplastics (MPs) are nowadays considered as ubiquitous pollutants: indeed, they have been found not only in the surroundings of urban environments, but also in secluded places such as submarine canyons and arctic ice [4]. It can be assessed that all the environmental compartments are contaminated: water [5,6], soil and sediments [4,7], air $[8,9]$, biota $[10,11]$. Usually MPs are considered every plastic fragment with main dimension lower than $5 \mathrm{~mm}$; typically a lower boundary of $1 \mu \mathrm{m}$ is used to mark out Nanoplastics (NPs) [2,3,12-14]. Indeed, there is no common definition among the EU countries or elsewhere. The European Chemical Agency (ECHA) hence proposed a "working definition" based on the substance, state, morphology and dimensions [15, 16]. MPs are also grouped according to their origin into primary and secondary MPs: the former are those designed purposefully as such, while the latter are the results of shattering and fragmentation of larger plastic debris, due to a combination of mechanical stress, UV radiation and (micro)biological degradation [2,17].

MPs cannot be defined positively harmless, since alterations to biota due to their exposure have been reported; however, the hazards related to MPs for humans have not been fully understood yet $[18,19]$. MPs will indeed be tackled in the new release of the EU drinking water directive

\footnotetext{
* Corresponding author.

E-mail address: margherita.barchiesi@uniroma1.it (M. Barchiesi).
} 
along with other emerging contaminants [20]. Furthermore, actions toward their reduction in the environment have also been suggested by the SAM (Scientific Advice Mechanism) Group of Chief Scientific Advisors to the European Commission [21]. Indeed, MPs are considered both in the Marine Strategy Framework Directive (MSFD) and the EU Plastic Strategy [17] and nominated as pollutants of concern in the EU review of the Urban Waste Water Treatment Directive (UWWTD) [22]. Research on MPs rocketed in the last decade, beginning with studies on the marine environment but broadening soon to other environmental compartments and to related toxicology. If some clarity on certain aspects have been achieved, such as their widespread presence, still the dearth of certainties regarding their effects and behavior compels to a massive effort in deepening the understanding of the topic. This review work aims at presenting an overview of what is known of MPs in the urban water cycle, focusing on the role of water treatment plants in spreading and control of MPs. A first section is hence dedicated to the presence of MPs in the water sources, a second section to the fate of MPs in drinking water treatment plants and their presence in drinking water, a third section is focused on the presence and fate in wastewater treatment plants, a fourth section is dedicated to the studies that tried to understand the link and role of wastewater treatment plants in modification and determination of microplastic pollution in water bodies. The last two sections aimed at connecting the information gathered to offer an overview of MPs in the urban water cycle and the possible future perspectives.

\section{Foreword on data comparison}

Data comparison is central and essential to researchers in order to evaluate the results obtained, validate them, frame them within the related context, understand likenesses and differences in distributions, trends and behaviors.

Up to now though there is no common framework for MPs sampling, sample pre-treatment, MPs identification, quantification and classification. This greatly affects the chance of retrieving information by comparison of literature data. Indeed, there is not only a lack of coherence in the data collected on microplastic presence in the various media involved, but even among studies related to the same environmental compartment.

The use of different methodologies for each step of the MPs analysis, results in not comparable data: for instance, a too small sample volume might hamper its representativeness, difference in targeted size range as in the solution used for density separation leads to different MPs concentration and characteristics, all identification techniques have diverse strengths and weaknesses. Moreover, there is neither a standardized size classification nor a common morphological classification [23].

Without precise information on the analytical protocols followed and the quality assessment conducted, the data showed are not even indicative and possibly misleading.

\section{Microplastics evidences in water sources}

MPs sources to water environments have been ascribed to many different origins. Galafassi et al. [24] reported an estimation of MPs inputs to water systems based on data from scientific and grey literature (i.e. non-conventional scientific publications, e.g. governmental reports, issues papers etc.). Sources considered were land-based and off-shore, including wastewater treatment plants, tires and roadways, municipal solid waste, primary MPs loss, blasting abrasive and paints [24]. The relevance of an effective waste management system was also underlined by Wong et al. [25]. According to Galafassi et al. [24], the higher contribution to MPs pollution was linked to tires and fragmentation of either litter or fishery and aquaculture equipment [24]. The authors also underlined how wastewater treatment systems achieved an important reduction of land-based sources originated from factories, buildings and urbanized areas. However, it was highlighted that even with the high retention capability of wastewater treatment plants towards MPs, large loads are discharged to the environment every day by these facilities [24]. Besides, the application of treated sludge for agricultural purposes turns them back into sources of MPs for the environment.

MPs fate and transport in water environments are influenced by many different factors, such as MPs density, shape and size, and also relations with biota. All such factors interact with the characteristics of the hosting waterbody: water flow velocity, water depth, bottom topography, seasonal variation of water flow, tidal cycle, storms, floods and anthropogenic activity (e.g. dam release) [25].

\subsection{Surface waters: rivers and lakes}

Regarding freshwaters, a comprehensive summary of the data available until 2019 about MPs in freshwaters is found in Rios Mendoza and Balcer [26]. Regardless of the un-homogeneity of the data, the authors drew the following main observations: in China there was the highest concentration of MPs in the world, being also one of the bigger plastic producer; urban areas tended to have higher concentration of MPs as compared to rural areas; stormwater retention ponds concentrated MPs [26]. Another rich source of data is the review by Schell et al. [27] where the authors compared studies using homogeneous units of measurements: i.e. they transformed the units of MPs/surface into MPs/volume, when it was possible. In conclusion it was assessed that MPs concentration in European freshwaters was in the interval 1-100 MP s $/ \mathrm{m}^{3}$, with some noticeable exceptions. The highest values were reported in the Snake River in North America $\left(5,405,000 \mathrm{MPs} / \mathrm{m}^{3}\right.$ ) and in Vietnam, while very high concentrations were found in Asia, specifically in China (as reported above). However, when including the MPs lowest size, the results did not differ significantly among the countries. The same authors highlighted that smaller particles were often the most frequent ones; they also underlined how different sampling protocols and devices led to significantly different results. Increasing MPs concentration were linked to urban areas. Fragments and fibers from Polyethylene (PE) and Polypropylene (PP) were the MPs most frequently found. The predominance of PE and PP, as of fibers and fragments, had been confirmed also by Li et al. [28]. "Temporal hotspots" in MPs concentration might be linked to weather conditions: storms and rainfall could increase the runoff and the sewage contribution, while floods could be related to the resuspension of sediments and hence of sedimented MPs [27]. The authors noticed how higher concentration was generally found in riverbeds compared to river beach and shore sediments [27]. The role of the hydrological features of rivers for the MPs sedimentation and the influence of winds, waves and beach morphology on their deposition on lake shores was also reported by many studies [27].

Following, the recent updates published in 2020, obtained on EbscoHost search engine of the University of Rome La Sapienza (a sum up of which is reported in the supplementary material), are summarized and commented.

Based on these papers, fibers, followed by fragments, were confirmed as the most common, as well as the smallest size fractions and PE and PP as most frequent polymers. However, there are also some studies who reported a prevalence of beads [29] or films [30,31]. Socio-economic features of the area under study are confirmed as relevant factors in determining MPs pollution. Table 1, obtained from the same list of 2020 studies, reports the factors mainly affecting MPs pollution. Particularly, the specific aspect and parameters are highlighted along a brief summary of the conclusions. Among these factors there are: hydrological and morphological characteristics of the catchment, weather and climate related phenomena and socio-economic factors. Specifically, the MPs abundance is strongly related to the Gross Domestic Product (GDP) of the area, as the presence and quantity of industries. On this account, it is worth of notice the attempt by Zhang et al. [32] at defining the relation between MPs abundance and the type of industry (primary, secondary, tertiary). These parameters are strictly followed by 
Table 1

Factors influencing MPs abundance in the environment.

\begin{tabular}{|c|c|c|c|}
\hline Topic & Ref. & Parameter & Main conclusions \\
\hline \multirow{8}{*}{$\begin{array}{l}\text { Analysis } \\
\text { methodology }\end{array}$} & 1 & Sampling device & $\begin{array}{l}\text { Statistically significant } \\
\text { difference in MPs } \\
\text { concentration upstream and } \\
\text { downstream WWTPs effluent } \\
\text { with a manta trawl net, no } \\
\text { statistically significant } \\
\text { difference with a pumping } \\
\text { device sampler }\end{array}$ \\
\hline & 2 & Sampling device & $\begin{array}{l}\text { MPs abundance and the fibre } \\
\text { content detected with a pump } \\
\text { sampling device was } \\
\text { significantly higher compared } \\
\text { to that recovered by plankton } \\
\text { nets }\end{array}$ \\
\hline & 3 & Sampling point & $\begin{array}{l}\text { Differences in MPs } \\
\text { concentration between the } \\
\text { left, middle and right section } \\
\text { of the stream }\end{array}$ \\
\hline & 4 & Sampling point & $\begin{array}{l}\text { MPs mainly distributed on the } \\
\text { surface compared to the other } \\
\text { depth levels }\end{array}$ \\
\hline & 5 & $\begin{array}{l}\text { GDP, population } \\
\text { density, (land use) }\end{array}$ & $\begin{array}{l}\text { Significant correlation of } \\
\text { parameters with MPs } \\
\text { concentration, (positive } \\
\text { correlation though not } \\
\text { significant with build-up land } \\
\text { use) }\end{array}$ \\
\hline & 6 & $\begin{array}{l}\text { GDP, population } \\
\text { density }\end{array}$ & $\begin{array}{l}\text { Significant correlation of } \\
\text { parameters with MPs } \\
\text { concentration }\end{array}$ \\
\hline & 7 & $\begin{array}{l}\text { Per capita GDP, } \\
\text { primary industry }\end{array}$ & $\begin{array}{l}\text { Significant correlation of } \\
\text { parameters with MPs } \\
\text { concentration, (correlation } \\
\text { though not significant with } \\
\text { population density, basin } \\
\text { area, runoff and tertiary } \\
\text { industry) }\end{array}$ \\
\hline & 8 & industrialization & $\begin{array}{l}\text { MPs concentration } \\
\text { significantly higher in } \\
\text { industrial areas }\end{array}$ \\
\hline \multirow{7}{*}{$\begin{array}{l}\text { Influence of socio- } \\
\text { economical } \\
\text { features }\end{array}$} & 9 & industrialization & $\begin{array}{l}\text { Packing industry as probable } \\
\text { source of the MPs }\end{array}$ \\
\hline & 10 & urbanization & $\begin{array}{l}\text { The predictors indicative of } \\
\text { urbanized areas (as } \\
\text { population density and urban } \\
\text { percent) were among the } \\
\text { highest in explaining MPs } \\
\text { abundance variation }\end{array}$ \\
\hline & 11 & urbanization & $\begin{array}{l}\text { The predictors related to } \\
\text { urban filters explained the } 22 \\
\% \text { of the variation, while } 15 \% \\
\text { was linked to MPs possible } \\
\text { source }\end{array}$ \\
\hline & 12 & urbanization & $\begin{array}{l}\text { No significant correlation } \\
\text { among MPs abundance and } \\
\text { distance from the city centre } \\
\text { No significant difference in }\end{array}$ \\
\hline & 13 & urbanization & $\begin{array}{l}\text { MPs abundance between } \\
\text { urban and rural area }\end{array}$ \\
\hline & 14 & urbanization & $\begin{array}{l}\text { Urban areas were not always } \\
\text { responsible of a significant } \\
\text { increase in MPs abundance }\end{array}$ \\
\hline & 15 & seasonality & $\begin{array}{l}\text { MPs concentration were } \\
\text { always higher in dry season } \\
\text { compared to wet season }\end{array}$ \\
\hline \multirow{4}{*}{$\begin{array}{l}\text { Weather and } \\
\text { climate } \\
\text { influence }\end{array}$} & 16 & seasonality & $\begin{array}{l}\text { MPs concentration were } \\
\text { always higher in dry season } \\
\text { compared to wet season } \\
\text { (limited) }\end{array}$ \\
\hline & & & Positive correlation between \\
\hline & 17 & rainfall & $\begin{array}{l}\text { MPs abundance and rainfall } \\
\text { events }\end{array}$ \\
\hline & 18 & Seasonality, flow & $\begin{array}{l}\text { No seasonality in UK river MPs } \\
\text { abundance and the relation }\end{array}$ \\
\hline
\end{tabular}

Table 1 (continued)

\begin{tabular}{|c|c|c|c|}
\hline Topic & Ref. & Parameter & Main conclusions \\
\hline & & \multirow{5}{*}{ Rainfall, flow } & $\begin{array}{l}\text { with flow was indicated as } \\
\text { "inconsistent" }\end{array}$ \\
\hline & 19 & & $\begin{array}{l}\text { Could not determine clear } \\
\text { patterns between MPs } \\
\text { abundance and river flow rate } \\
\text { or rainfall (sampling } \\
\text { difficulties in flood } \\
\text { conditions) }\end{array}$ \\
\hline $\begin{array}{l}\text { Spatial vs } \\
\text { temporal } \\
\text { variations }\end{array}$ & 20 & & $\begin{array}{l}\text { Spatial variations (as in } \\
\text { geographical, demographical } \\
\text { or WWTPs inputs) had higher } \\
\text { influence on MPs abundances } \\
\text { than temporal variation (as in } \\
\text { flow or wind conditions) }\end{array}$ \\
\hline \multirow[b]{2}{*}{$\begin{array}{l}\text { Influence of } \\
\text { hydrological } \\
\text { features }\end{array}$} & 21 & & $\begin{array}{l}\text { Higher MPs concentration was } \\
\text { found at rivers mouth }\end{array}$ \\
\hline & 22 & & $\begin{array}{l}\text { Higher concentration in the } \\
\text { inner and outer bends of the } \\
\text { river compared to the straight } \\
\text { tracts }\end{array}$ \\
\hline
\end{tabular}

Ref. 1 [40], 2 [32], 3 [41], 4 [36], 5 [33], 6 [42], 7 [32], 8 [40], 9 [43], 10 [44], 11 [29], 12 [45], 13 [37], 14 [39], 15 [46], 16 [43], 17 [41], 18 [39], 19 [38], 20 [47], 21 [31,35,36], 22 [37].

population density and land-use. The differentiation between rural and urban areas is though not well defined. Their relative influence on the MPs abundance is also related to the surroundings state in terms of pollution and catchment characteristics, of morphology and flow regime. Indeed, if urban areas are often characterized by higher MPs pollution, the difference compared to the surroundings is not always significant nor confirmed. Also, the hydraulic characteristics of the water body and anthropic changes are put under the spotlight by some authors: Huang et al. [33] observed a noticeable decrease in MPs abundance in water downstream the river dam, while Dahms et al. [34] did not notice a difference in MPs abundance in water, while observed higher MPs abundance in sediments and biota upstream. River mouths appears to be often a concentration spot for MPs, while the straight tracts seem to ease MPs flow along the river compared to inner and outer bends [31,35-37]. Atmospheric deposition is also considered: Constant et al. [38] evaluated the role of MPs atmospheric deposition as possibly significant; by contrast, Stanton et al. [39] considered such contribution being not important but argued that the low values recorded could be linked e.g. to the sampling height and other various environmental and meteorological factors. Regarding weather related phenomena, the increase of MPs pollution due to rainfall might be linked to the contribution given by the urban drainage collecting MPs otherwise deposited on urban surfaces; the rain events of high intensity could easily clean urban surfaces conveying a first peak followed by dilution. A higher concentration of MPs is expected during dry season due to the reduced effect of dilution with respect to the wet season. All these hypotheses need confirmation and critical proof.

Regarding specifically MPs sources to water bodies, it is interesting the approach applied by Grbic et al. [44] to assess the relevance of stormwater and agricultural runoff. They found MPs in all streams, with noticeably a $22 \%$ of tire and road wear particles in the urban runoff and nowhere else; they also noticed polymers related to agricultural activities in the agricultural runoff.

These reviews and studies show that space and time variations are important factors to assess the MPs pollution in surface waters. Moreover, a careful evaluation of sampling points, methods and time has to be always considered in MPs research.

\subsection{Groundwaters}

Information on MPs in groundwaters are rather scant. The MPs found in two Illinois karst aquifers were mostly fibers along with other 
pollutants, that suggested septic effluents as the source; however, the authors underlined the need for further studies [48]. The characteristics of the polymers found by Mintenig et al. [49] led the authors to the conclusion that the MPs contamination was mostly due to abrasion during the drinking water supply chain or to airborne contamination during the analysis [49]. Another evidence of MPs in groundwater is offered by Ganesan et al. [50] who found PET and Polyamide in the groundwater of Tamil Nadu, India. The consideration of the multiple possible paths for MPs into groundwaters, the transportation within and the relevance of those as water sources [51], is urging for a more extensive survey.

\section{Microplastics presence and fate in drinking water treatment plants}

Evidences of MPs in drinking water were first collected in 2017 by a "not peer-reviewed" research work published later on with PLOSONE [52]. In 2018 other data appeared in scientific journals [53-56], whereas the World Health Organization (WHO) commissioned a report on the presence and possible hazards of MPs in drinking water [19]. In the review on MPs in freshwaters and drinking water by Koelmans et al. [57] a first assessment of data quality was attempted. Other review works were then developed, as that published by Eerkes-Medrano et al. [58]. In the paper by Akhbarizadeh et al. [59] focus was on bottled water, whereas Novotna et al. [60] and Shen et al. [61] addressed the fate of MPs in the drinking water treatment plants. Evidences of MPs at the end of the water supply chain are uncanny, though origin and cause of pollution are far to be fully cleared. Plastics in bottled water might indeed significantly be linked to the packaging material and its wear; however, presence of MPs in glass bottled water suggests also different origins of the pollution [59]. According to the studies until now published, MPs found at the outlet of drinking water treatment plants vary noticeably in concentration, from 0 [49] to $930 \mathrm{MPs} / \mathrm{L}$ [62] due to the different water sources, plant layout and analytical methods. The chance of contamination by the water supply chain purification and conveying equipment is also suggested [49].

Drinking water treatment plants (DWTPs) are not designed specifically to treat MPs, though the removal of solids and colloids is a specific obligation to the obtainment of potable water. MPs belong indeed to the "solids" category. Features relevant to understand the treatment efficiency are the MPs size, morphology and polymer composition as their surface characteristics. On this account, MPs are defined as hydrophobic [19], while polymers surface charge is reported in Novotna et al. [60]. The possible interactions with the various treatment processes employed in the water treatment sector were analyzed by Enfrin et al. [3] and Shen et al. [61], although the experimental data available are few. To which extent DWTPs are able to purify raw water from MPs has been studied at whole scale by a limited number of works. The results are reported in Table 2 and discussed below, whereas the few bench-scale experiences are summed up in Table 3.

The first study reported in Table 2 evaluated the treatment efficiency of three different DWTPs. The change in the relative abundance of MPs morphology suggested the possible presence of a relationship between shape and removal [54]. The second study evaluated instead the presence of MPs in various points of the drinking water supply chain, including the inlet and outlet of a plant treating groundwater. The microplastic presence was found to be very low; it was hypothesized that its origin could be linked to atmospheric or supply chain contamination [49].

The third study cited in the table is the first one, to the best knowledge of the authors, to report the removal efficiency for MPs particles at each step of the water treatment line of a DWTP [62]. MPs size distribution, morphology and composition were also assessed at each step, and possible relations between such characteristics and the removal efficiency was considered. No MPs $>50 \mu \mathrm{m}$ were found in the effluent and the relative percentage of the $1-5 \mu \mathrm{m}$ increased. Ozonation caused an apparent slight increase in MPs abundances, due to the shear forces exerted by the flow. The authors hypothesized also an increased efficiency in identification due to the more effective organic matter digestion of the sample by the pre-treatment step, favored by the ozone oxidation occurred in the water treatment line. The GAC step removed partially the MPs from the ozonation effluent, though the mechanism responsible was unclear [62].

Based on the reported data, it can be assessed that DWTPs contribute to a significant reduction of MPs, also when treating surface waters where the influent load is higher. Moreover, the CFS + SF + GAC layout seems to able to remove above $80 \%$ of influent MPs, according to the data of the second DWTP of the first study (WT2) and the DWTP considered in the third research (which included ozonation too) $[54,49]$. Furthermore, it is confirmed the higher selective removal of fibers, [54, 62], possibly related to the plant layout [54]. In general, the most challenging size fraction seems to be the smallest, being the harder to remove and therefore frequently found in the effluents (see Table 2). The interactions with other parameters, such as inflow water quality and DWTPs process characteristics, are to be still further investigated. Hence more studies are required to drive more conclusive deductions on all these aspects.

Regarding specifically the coagulation process, put under the spotlight being one of the most used to obtain and enhance solid-liquid separation, from the bench scale studies it seems that at the coagulants dose used at full scale, the removal efficiencies are low and anyhow size dependent. The optimization of the operative parameters is hence still to be defined. The reported efficiency by CFS in a full scale DWTP though was higher compared to that obtained at the bench scale

Table 2

Studies on the removal efficiency of DWTPs towards MPs.

\begin{tabular}{|c|c|c|c|c|c|c|c|c|c|}
\hline Ref. & P.Q.I & $\begin{array}{l}\text { Size } \\
\text { target }\end{array}$ & Source & Treatment layout & IN & \multicolumn{3}{|c|}{ OUT } & $\mathrm{R} \%$ \\
\hline 1 & $\begin{array}{l}\text { WPO; SEM, FTIR, } \\
\text { RAMAN }\end{array}$ & $\begin{array}{l}1 \mu \mathrm{m}- \\
5 \mathrm{~mm}\end{array}$ & $\begin{array}{l}\text { water } \\
\text { reservoir } \\
\text { water } \\
\text { reservoir } \\
\text { river }\end{array}$ & $\begin{array}{l}\mathrm{CF}+\mathrm{SF}(\mathrm{WT} 1) \\
\mathrm{CFS}+\mathrm{SF} \text { and GAC (WT2) } \\
\mathrm{CF}+\text { flot }+\mathrm{SF} \text { and GAC } \\
\text { (WT3) }\end{array}$ & $\begin{array}{l}>10 \mu \mathrm{m} \text { only } \\
10 \% \mathrm{c} . \mathrm{a} \\
\text { Fragments } \\
\text { PET + PP }\end{array}$ & $\begin{array}{l}1473 \pm 34(\mathrm{WT} 1) \\
1812 \pm 35(\mathrm{WT} 2) \\
3605 \pm 497 \\
(\mathrm{WT} 3) \\
\text { MPs/L }\end{array}$ & $\begin{array}{l}<10 \mu \mathrm{m} \\
\text { prevails } \\
\text { Fragment } \\
\text { PET + PP }\end{array}$ & $\begin{array}{l}443 \pm 10 \\
(\text { WT1) } \\
338 \pm 76 \\
(\text { WT2) } \\
628 \pm 28 \\
(\text { WT3) } \\
\text { MPs/L }\end{array}$ & $\begin{array}{l}70 \text { (WT1) } \\
81 \text { (WT2) } \\
83 \text { (WT3) }\end{array}$ \\
\hline 2 & $\begin{array}{l}\mathrm{HCl}+\mathrm{H}_{2} \mathrm{O}_{2}+ \\
(\mathrm{ZnCl} 2) \\
\text { FTIR }\end{array}$ & $\begin{array}{l}3 \mu \mathrm{m}- \\
5 \mathrm{~mm}\end{array}$ & groundwater & Filtration + aeration & \multicolumn{4}{|c|}{$0-7 \mathrm{MP} s / \mathrm{m}^{3}$. All 50-150 $\mu \mathrm{m}, \mathrm{PEST}, \mathrm{PVC}, \mathrm{PE}, \mathrm{PA}$ and epoxy resin } & n.a \\
\hline 3 & $\begin{array}{l}\mathrm{H}_{2} \mathrm{O}_{2}+ \\
\text { SEM + RAMAN }\end{array}$ & $\begin{array}{l}0.2 \mu \mathrm{m}- \\
5 \mathrm{~mm}\end{array}$ & river & $\mathrm{CFS}+\mathrm{SF}+$ ozonation $+\mathrm{GAC}$ & $\begin{array}{l}1-5 \mu \mathrm{m} \text {, fibers } \\
\text { PET, PE }\end{array}$ & $\begin{array}{l}6614 \pm 1132 \\
\text { MPs/L }\end{array}$ & $\begin{array}{l}1-5 \mu \mathrm{m} \\
\text { fibers } \\
\text { PET; PE }\end{array}$ & $\begin{array}{l}930 \pm 72 \\
\text { MPs/L }\end{array}$ & $82.1-88.6$ \\
\hline
\end{tabular}

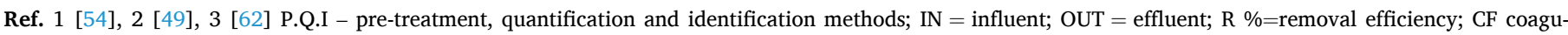
lation/flocculation; CFS coagulation/flocculation/sedimentation; GAC granular activated carbon; SF sand filtration; flot. floatation. 
Table 3

Bench scale studies on MPs removal in water treatment plants.

\begin{tabular}{|c|c|c|c|c|}
\hline Ref. & Process & $\begin{array}{l}\text { Observations } \\
\text { on methods }\end{array}$ & Main results & Notes \\
\hline 1 & $\begin{array}{l}\text { CFS, } \\
\text { ultrafiltration }\end{array}$ & $\begin{array}{l}\text {-High } \\
\text { dimension of } \\
\text { particles used } \\
\text {-Only PE } \\
\text { particles } \\
\text { evaluated } \\
\text { (supposedly } \\
\text { fragments) } \\
\text {-No fibers } \\
\text { included }\end{array}$ & $\begin{array}{l}\text { Al-based salts } \\
\text { performed } \\
\text { better, although } \\
\text { at dosage } \\
\text { typically used in } \\
\text { water works the } \\
\text { removal was } \\
\text { only of } 8 \% \text {. } \\
\text { Increasing the } \\
\text { dose to } 405 \mathrm{mg} \text { / } \\
\text { L Al ( } 15 \mathrm{mmol} / \\
\text { L), removal } \\
\text { efficiency of } \\
\text { about } 37 \% \text { was } \\
\text { obtained. } \\
\text { High removal } \\
\text { efficiency } \\
\text { obtained by } \\
\text { polyacrylamide } \\
\text { (PAM). } \\
\text { Complete } \\
\text { removal } \\
\text { obtained by } \\
\text { ultrafiltration. }\end{array}$ & $\begin{array}{l}\text {-Novotna et al. [60] } \\
\text { observed how the } \\
\text { need of coagulation } \\
\text { for removing } \\
\text { particles of the } \\
\text { order of millimeters } \\
\text { is doubtful, being } \\
\text { usually devoted to } \\
\text { the removal of } \\
\text { colloidal solids. } \\
\text {-Shen et al. [61] } \\
\text { and Novotna et al. } \\
\text { [60] observed how } \\
\text { the PAM added } \\
\text { exceeded by far the } \\
\text { maximum allowed } \\
\text { by WHO for } \\
\text { drinking water. } \\
\text {-Novotna et al. [60] } \\
\text { underlined how the } \\
\text { presence of much } \\
\text { smaller MPs is } \\
\text { expected in DWTPs } \\
\text { compared to those } \\
\text { used in the study } \\
\text { (indeed confirmed } \\
\text { by the studies } \\
\text { previously reported } \\
\text { in Table 2), hence } \\
\text { the partial } \\
\text { usefulness of the } \\
\text { results obtained } \\
\text { [60]. }\end{array}$ \\
\hline 2 & CFS, filtration & $\begin{array}{l}\text { Particles size } \\
\text { range } \\
(<125 \mu \mathrm{m}) \\
\text { and amount, } \\
\text { polymers used } \\
\text { (PE, PS), } \\
\text { coagulants } \\
\text { dosage and } \\
\text { filtration } \\
\text { parameters } \\
\text { chosen to } \\
\text { resemble as } \\
\text { much as } \\
\text { possible those } \\
\text { of a full scale } \\
\text { DWTP. Test } \\
\text { performed on } \\
\text { clean } \\
\text { particles, } \\
\text { afterwards } \\
\text { one size class } \\
\text { is chosen, and } \\
\text { processes } \\
\text { evaluated on } \\
\text { MPs colonized } \\
\text { by biofilm } \\
\text {-No fibers } \\
\text { included }\end{array}$ & $\begin{array}{l}- \text { Removal }<2 \% \\
\text { for all size } \\
\text { classes with Al } \\
\text { coagulant at full } \\
\text { scale DWTP } \\
\text { dosage. } \\
\text {-removal } \\
\text { increase with } \\
\text { PolyDADMAC } \\
\text { (max. of } 13.6 \% \text { ) } \\
\text {-Higher removal } \\
\text { efficiency by } \\
\text { filtration on } \\
\text { anthracite (from } \\
\text { 86.9\%-99.9\%) } \\
\text {-Effect of biofilm } \\
\text { is significant on } \\
\text { CFS removal of } \\
\text { microplastics } \\
\text { (increase to } 16.5 \\
\% \text { ), no } \\
\text { significant } \\
\text { variation for } \\
\text { filtration. }\end{array}$ & $\begin{array}{l}\text { - No significant } \\
\text { difference in } \\
\text { removal } \\
\text { percentages among } \\
\text { the size classes with } \\
\text { Al coagulant } \\
\text { - PolyDADMAC: } \\
\text { significant removal } \\
\text { increase. for the } \\
\text { 45-54 } \mu \text { m particles } \\
\text { - Low removal } \\
\text { efficiency obtained } \\
\text { are most probably } \\
\text { linked to the } \\
\text { buoyant nature of } \\
\text { the plastic used for } \\
\text { the trial } \\
\text { - Wide differences } \\
\text { among size classes } \\
\text { and not } \\
\text { proportional to the } \\
\text { change of particles } \\
\text { size for removal } \\
\text { efficiencies by } \\
\text { filtration } \\
\text { - CFS removal on } \\
\text { MPs with biofilm: } \\
\text { change in particle } \\
\text { size and density } \\
\text { plus the production } \\
\text { of Extracellular } \\
\text { Polymer Substance } \\
\text { (EPS), promote } \\
\text { aggregation and } \\
\text { sinking rate. } \\
\text { Besides, } \\
\text { microorganism's } \\
\text { colonization might } \\
\text { result in } \\
\text { fragmentation of }\end{array}$ \\
\hline
\end{tabular}

Table 3 (continued)

\begin{tabular}{|c|c|c|c|c|}
\hline Ref. & Process & $\begin{array}{l}\text { Observations } \\
\text { on methods }\end{array}$ & Main results & Notes \\
\hline 3 & $\begin{array}{l}\text { Disinfection } \\
\text { by chlorine } \\
\text { agents }\end{array}$ & & & $\begin{array}{l}\text { the particles } \\
\text { lowering filtration } \\
\text { efficiencies } \\
\text { HDPE and PP } \\
\text { seemed to be quite } \\
\text { resistant to } \\
\text { commonly used } \\
\text { dosage while PS } \\
\text { was an exception: it } \\
\text { shows indeed } \\
\text { detectable changes } \\
\text { in structure even at } \\
\text { CT values as low as } \\
75 \text { and } \\
150 \mathrm{mg} \text { *min/L [66] }\end{array}$ \\
\hline
\end{tabular}

Ref 1 [63], 2 [64], 3 [66].

[62]: this can be linked to the different size range evaluated by the studies and also to the higher variety of MPs in raw water compared to the synthetic one used for the bench scale studies. Indeed, at full scale, the size-related removal is confirmed by a higher retainment of the bigger particles; however, the shape mostly retained were fibers, not included in the bench scale studies [62-64]. Concerning filtration on whatsoever matrix, much needs to be unveiled too: the interactions between MPs and the solids are still unclear as well as the effect of operational parameters (e.g. flow velocity, backwash time). Anyway, the removal efficiencies reported for $\mathrm{CF}+\mathrm{SF}$ seems to be around 60-70 $\%$ [54,62]. Regarding membrane processes for drinking water treatment, plenty is still to be uncovered, beginning with the behavior of membrane towards different MPs morphology classes and sizes. A step forward in this direction can be considered the study by Enfrin et al. [65] specifically tackling the kinetic and mechanistic aspects of membrane fouling by MPs and NPs [65]. The chemical agents used in oxidation and disinfection might have some effects on the particles but this aspect is also yet to be fully assessed $[62,66]$.

\section{Microplastics presence and fate in wastewater treatment plants}

Wastewater treatment plants (WWTPs) receive sewage from the pertinent area and treat it in order to abide by the discharge limit regulations. Contaminants targeted by wastewater directives are mainly solids, organic matter, nutrients and pathogens. Wastewater treatment plants are hence not designed to specifically remove MPs [67]. Sources of MPs to wastewater treatment plants are directly linked to the flow origin: separate or combined sewage systems, domestic or industrial wastewater, landfill leachate. Separate systems convey wastewater from household appliances and commercial or industrial wastewater. For instance, MPs due to domestic discharge are mainly linked to the Personal Care Products (PPCP) (as exfoliants, toothpaste) and fibers from synthetic clothes washing [68], while MPs of industrial origin are mainly related to air blasting applications and water discharge by plastic items production factories [69,70]. MPs in landfills leachate are connected to the degradation processes that plastic items undergo in the peculiar environmental conditions that establish in the landfill itself: causes of modification for the polymers are indeed the varying $\mathrm{pH}$ conditions, the formation of gases and aggressive compounds as the changes in mechanical stress [71]. Combined sewage systems deliver to the WWTP the water from the urban runoff too, hence implying the presence of MPs linked to the embrittlement of larger plastic debris found on the urban ground, tires fragments due to friction with roads surface [67] and MPs from atmospheric deposition [69]. Indeed, Sun et al. [67] reported in their review evidences of increasing MPs concentration in influent linked to combined sewage collecting systems, 
probably due to the urban runoff gathered. Stormwater retention ponds have been found as hotspots for MPs pollution, being moreover those related to industrial and commercial area more polluted than those linked to highway and residential areas [72].

An overview of the fate of MPs along the whole water treatment line was compiled by Carr et al. [73] where the findings from 8 WWTPs of Southern California were reviewed and compared to the other researches available at that time. Each step of the treatment was analyzed in light of MPs characteristics and the possible removal processes were pinpointed. Same approach was followed by Ngo et al. [69] in a very comprehensive analysis of the literature on MPs in WWTPs, addressing also the sources and pathways to the plants. In Sun et al. [67], it was instead deeply analyzed the MPs analytical protocols (updated later on by Bretas-Alvim et al. [74]) as well as the characteristics of MPs in wastewaters and their fate in WWTPs. Sludge was explicitly targeted by Lusher et al. [75] and Rolsky et al. [76]. Among the latest reviews of peculiar interest is the one compiled by Schell et al. [27] on freshwater and terrestrial ecosystems: here a specific section on WWTPs was also included, presenting one of the most up to date gathering of information on this topic. Another complete summary of the data is found in the article by Birch et al. [77].

\subsection{Influent to WWTPs}

Data on the MPs concentration in the influent to the WWTPs vary highly among the literature researches: to the best knowledge of the author, the highest value recorded until now is 10,044MPs/L related to a $10 \mu \mathrm{m}$ finest mesh [78], while the lowest value is $1.5 \mathrm{MPs} / \mathrm{L}$ related to a $26 \mu \mathrm{m}$ finest mesh [79]. Lower values were reported by Carr et al. [80] and Mason et al. [81] but without a chemical identification [80,81]. Such a variability might be linked to external factors such as the characteristics of the served area, weather, season, type of sewage collecting system and plant treatment capacity; however, it might also have origin from the applied measurement protocol. Therefore, understanding the influence of the external factors is possible only for those researches that analyzed more WWTPs, where results of different plants can be considered comparable aside of the applied analytical protocols. The information on the influence of socio-economic factors and weather-related factors on the influent to WWTPs as the observation of time-related patterns are summed up in Table 4.

The presence of industrial wastewater can influence the characteristics of the inflow to a WWTP, especially in terms of polymers abundance, morphology and variety $[70,84]$. The specific contribution of industrial effluents to the WWTPs in terms of MPs could hence be considered of importance, although not yet defined precisely in its quantity nor quality [88]. Therefore, it is relevant to define the characteristics of the industrial contribution to MPs inflow to WWTPs, for a better choice of the remediation strategies. Regarding possible daily or seasonal variation, the information available do not allow for some clarity and more studies are required for a better understanding of the issue.

Another important aspect to consider is the potential link with other pollutants. For instance, a strong linear relationship between MPs and suspended solids was indicated by Long et al. [70], whereas Bayo et al. [85] noticed an inverse relationship [85]. Bayo et al. [85] found also significant inverse relations between high COD influent and PS and PET abundance. Moreover, in the same paper it is reported an inverse relation between influent MPs and nutrients in the outflow, justified by the possible adsorption of nutrients on the MPs surfaces [85].

Regarding raw wastewater characteristics, Ngo et al. [69] noticed fibers and fragments as the main fractions in WWTPs influent (average of $56.7 \%$ and $34.4 \%$, respectively), while the most common polymers were PE and PP (ranging 11-42 \% and 3-32\%, respectively), PET (up to $42.26 \%)$, PES (79.1 \%) and PA (61.2 \%) [69]. Regarding MPs size, Sun et al. [67] reported how often the fraction $>500 \mu \mathrm{m}$ was the most present. Raju et al. [89] found instead increasing frequency with decreasing
Table 4

Factors influencing influent characteristics.

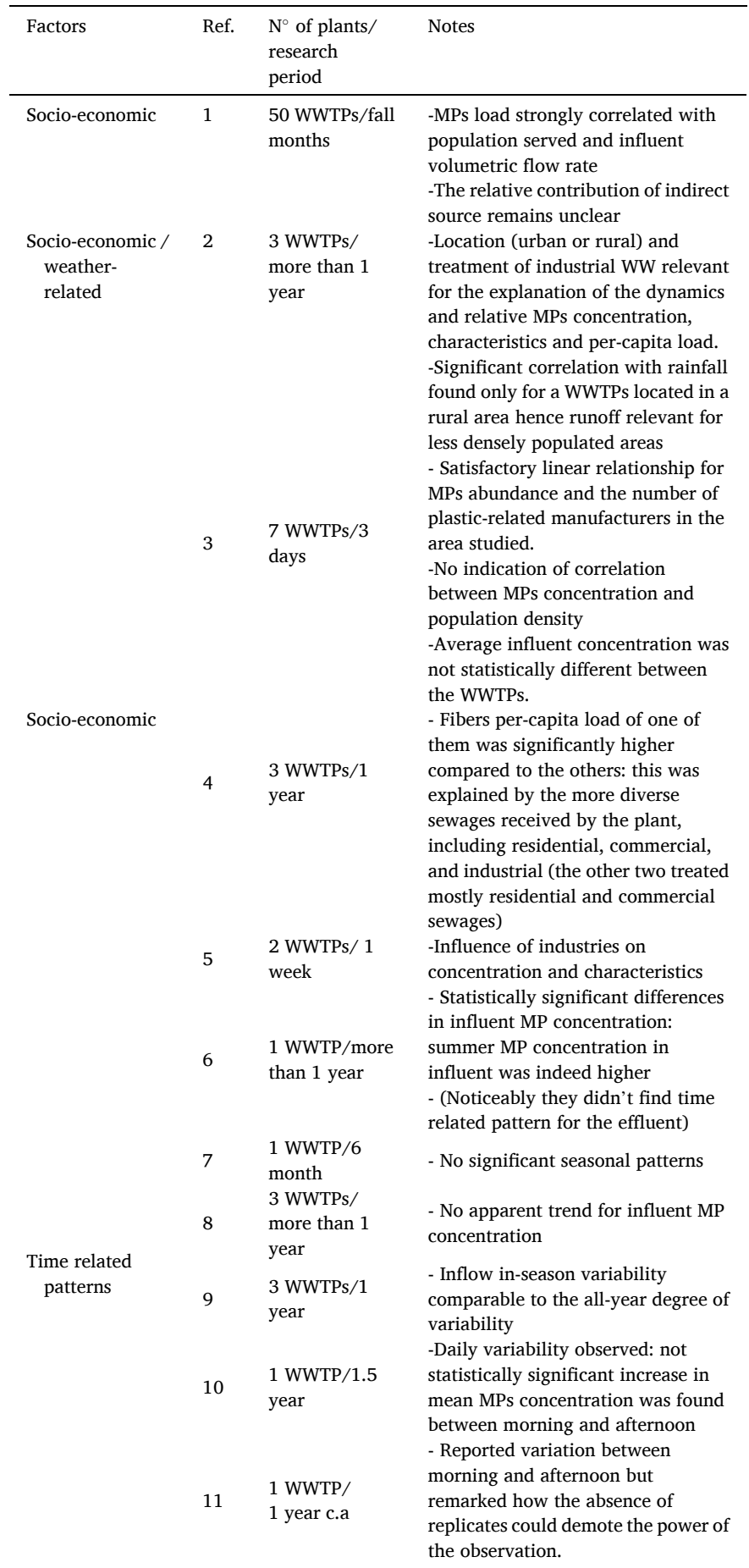

Ref. 1 [82], 2 [79], 3 [70], 4 [83], 5 [84], 6 [85], 7 [86], 8 [79], 9 [83], 10 [85], 11 [87].

size range, with highest percentage within $1.5-38 \mu \mathrm{m}$ : often overlooked lower size classes could indeed contain more MPs. Finally, Simon et al. [78] found that the influent concentration of MPs to 10 WWTPs was not normally distributed in terms of particle numbers nor of mass; however, they did not deepen the understanding of the differences among the WWTPs.

Conclusively, influent load of MPs to WWTPs and their characteristics seem to be possibly influenced by various factors: source of MPs (industrial, domestic...), population served, sewage collecting system, 
rainfall and seasonality. It is still to be understood which of these characteristics have the higher effect and the relative contribution in different contexts. Regarding time related patterns, although some data are reported, definite conclusions cannot be drawn (Table 4).

\subsection{Fate of MPs in WWTPS}

According to the review by Ngo et al. [69], fibers are the most difficult items to be removed, whereas PE and PP, most abundant in the influent, are almost absent in the effluent, because being removed by skimming due to their low density. By contrast, according to Fahrenfeld et al. [90], fibers and films are the best removed items. This disagreement is probably linked to the different characteristics in terms of the plant layout and analytical protocols used in the studies reviewed. The overall MPs removal efficiency found in the literature ranges from about $60 \%$ to $99.9 \%$. Among the factors influencing the removal efficiency, the plant layout and the technology are of sure relevance [69]. The analytical protocols used for the evaluation of MPs may also play a role: as already explained in the previous sections, different analytical protocols lead to different fractions of MPs extracted from the samples. Therefore, the calculated removal efficiencies are possibly different not only for MPs overall abundance, but also for the different classes used for their characterization (e.g. removal of fibers, fragments).

Regarding pre- and primary treatments, the reported removal efficiency by Ngo et al. [69] varied from $40.7 \%$ up to $91.7 \%$ : this was not only related to the presence or absence of an aerated grit chambers but also to the influent characteristics in terms of polymer types [69]. The authors also argued how fibers were the less removed items at these steps [69]. Sun et al. [67] also reported based on their literature analysis a removal range of $35-59 \%$ in pre-treatments and 50-98 \% after primary treatments, linking these values to the MPs density too, with the lighter being removed by skimming and the heavier by settling. They added that the pre-treatments had the largest impact in MPs relative size distribution, being able to remove those of larger size. Noticeably it is here argued how fibers were more effectively removed by pretreatments than fragments, noticing a decrease in the relative abundance of fibers after the pretreatments [67].

Regarding secondary treatments, considering "activated sludge and sedimentation", Ngo et al. [69] reported removal efficiencies in the range $28.1-66.7 \%$ related to different configurations (aerobic tank, succession of anaerobic, anoxic and aerobic). According to the authors, a longer retention time boosts the growth of biofilms on MPs, resulting in increased weight and flocs entrapment and therefore a better removal. The authors underlined anyway the need of further research on the topic [69]. In some studies, MPs overall removal obtained by secondary treatments was higher than $90 \%[82,85,91,92]$.

Sun et al. [67] reported a further decrease in the secondary treatments of $0.2-14 \%$ compared to the primary treatments. and confirmed the unknown interactions between flocculants, microbes and MPs, as well as the relevance of retention time and nutrients. Moreover, fragments appeared to be removed more than fibers: the authors noticed indeed an increase in relative abundance of fibers after secondary treatments, followed by a decrease in higher size MPs classes, even if with some exceptions [67]. Lower removal of fibers by secondary treatments was indeed confirmed also by recent papers [85,89]. Park et al. [82] found a higher relative abundance of fibers in the effluent as compared to the influent. However, this could be linked to the different sampling devices used for the two streams: compared to the influent (grab sampling), filtration time of the effluent on site is longer due to the higher volume to sample, hence the fibers have a higher chance of slipping through the sieves [82]. In Bayo et al. [85], a statistically significant removal of MPs larger fractions by the main WWTPs processes is observed, decreasing the mean size of MPs along the treatment line until the biological reactor (water treatments included grease and grit removal, primary clarifier and biological reactor). The mean size increased a little in the effluent [85]. Raju et al. [89] noticed how PET and PS were the most abundant in sludge compared to other low-density polymers, confirming the role of density during separation by sedimentation. The different removals reported by the various papers can be related to the various secondary treatments and operational conditions applied in the plants, and the different size and types of MPs.

According to Ngo et al. [69] the Membrane Biological Reactor (MBR) is the best technology for MPs-containing wastewater treatment, reaching consistently removal efficiency higher than $99.5 \%$. The authors underlined anyway the need of research on fouling and liquid distribution after a period of operation [69].

Indeed, Bayo et al. [86] noticed how, in a WWTP in Spain during eighteen months of observations, MBR process showed higher removal efficiency than CAS + RSF (79.01\% vs $75.49 \%$ respectively) though the difference was not statistically significant. The removal percentages reported by this work were not as high as could be expected, but coherent with Raju et al. [89] who examined a wider MPs size range [89]. Bayo et al. [86] found also statistically significant differences in MPs particles removal as compared to fibers for the conventional activated sludge plus rapid sand filtration (CAS + RSF) and the Membrane Biological Reactor (MBR) [86]. The authors confirmed moreover the different removal of polymers: indeed, of the 14 polymers detected in the influent, only melamine (MUF) was found in the effluent from the MBR. whereas LDPE, nylon and polyvinyl were detected in the effluent from RSF.

Tertiary treatments removal efficiency was well summarized by Sun et al. [67]: membrane processes are considered a reliable solution to MPs pollution whereas filtration systems (e.g. disc filters, rapid sand filtration, others) are not as dependable. Rapid sand filtration (RSF) showed significant inconsistences in the removal rate of MPs according to Ngo et al. [69] too. Sun et al. [67] added that biological aerated filters (BAF) and maturation ponds did not significantly change the MPs amount in the effluents [67].

Finally, Park et al. [82] found that plants supplied with advanced phosphorous removal processes showed significantly higher removal efficiencies [82].

Regarding effluent characteristics, Freeman et al. [93] reported how polyester microfibers and polyethylene microparticles are the most found in WWTPs effluents, whereas according to Sun et al. [67] MPs of the smallest size fractions are most common. For some authors, the lowest size classes have indeed the higher frequency [89,91,92]; however, other authors do not confirm this finding [79].

Regarding effluents time related patterns, Bayo et al. [85] found no significant difference among seasons. Weather related events appear to have significant relevance in some cases, as indicated by Mintenig et al. [49] where noticeably higher concentration was found in the effluent in a time frame including a strong rain event. This finding was already underlined by Wolff et al. [94], who indicated as responsible the higher flow velocity and hence poorer settleability of the particles. Long et al. [70] found also a strong relationship between effluent MPs concentration and the operating load of the WWTPs.

Conclusively, fibers appear to be the less retained by the WWTPs and the most abundant in the effluent along with the fragments. The effects of WWTPs on the size distribution and polymers variety has not been completely cleared yet. Regarding plant layout, pre- and primary treatments have a significant role in MPs removal; the effect of the secondary and tertiary treatments depends upon the technology chosen, although a significant removal is often obtained by the secondary treatments. The relevance of operational parameters has to be deepened: based on the available data, it seems that the lower the hydraulic retention time of the whole plant, the lower the MPs removal. About tertiary processes, membranes are more efficient and reliable than filtration in retaining MPs. Concerning temporal related patterns, there are recorded evidences, but no definitive conclusion can be driven: more comparable information is needed for the evaluation of such variations. 


\subsection{Presence and fate of MPs in sludge}

MPs presence in the sludge is a direct consequence of MPs removal from the water treatment line. Those MPs removed by preliminary treatments are disposed without further treatments and are likely to end up in landfills or incinerated. Instead, MPs embedded within sludges, follow these in the sludge treatment line. If MPs concentration in sewage sludge has been verified in different points of the treatment line by several studies, the effect of sludge treatments on MPs is yet to be fully cleared. Lusher et al. [75] provided a comprehensive table with studies carried out until 2019, considering different WWTP layouts for the water and sludge treatment line, and also MPs concentration and main characteristics [75]. Studying the available literature, Lusher et al. [75] observed how the inhomogeneous analytical protocols applied did not allow for a proper comparison among studies. However, general agreements among studies can be found on some aspects: concentrations are higher when smaller fractions are included in the analysis, alteration in shape and size might indicate an influence of sludge treatment processes [75]. The studies evaluating MPs in different steps of the sludge treatment line are hardly found. Lares et al. [13] took samples from activated sludge and digested sludge, while Talvitie et al. [95] sampled excess and dried sludge: both did not clarified about the possible effects of the different sludge treatments. Edo et al. [92] sampled sludge from the anaerobic digester and the commercialized pellets at the end of the sludge treatment line and noted how processing the sludge at $300{ }^{\circ} \mathrm{C} \mathrm{did}$ not alter significantly the MPs particles. Xu et al. [96] studied the sludge profile in a WWTP in China over three months and detected an increase in MPs content in the sludge probably linked to the rainfall conveying urban runoff to the plant. Regarding MPs characteristics, Edo et al. [92] noted that MPs in sludge were on average smaller than those in wastewaters and that the relative abundance of fibers was higher than in wastewaters. Potential fragmentation as well as melting and blistering have been reported, linked to high $\mathrm{pH}$ and mechanical mixing in lime stabilization and to heat drying [75]. Another aspect to give attention to is the role of rejected water, reported to release about $20 \%$ of MPs back to the water treatment line where it is recirculated [75].

Information on the effect of the sludge treatment line on MPs is clearly scant and not directly comparable when considering the different sampling and analytical procedures. It is clear how treated sludge could represent another source of MPs to the environment: there are indeed studies that demonstrated how the application of sludge in agriculture and sludge-based fertilizers caused MPs accumulation in soil [97-99].

\subsection{Linking the sources to the receivers: the WWTPs case}

It has been assessed that WWTPs can be considered a source of MPs to the environment; however, their specific role in water sources MPs pollution still requires a better understanding. Besides, it is of utmost interest the identification of potential removal and reduction of the MPs pollution achievable through WWTPs.

MPs source apportionment has hence become a fundamental task to be solved, but how to realize it based on the field results is still a matter of debate. A strategy could be the study of MPs morphology. Helm [100] suggested the definition of a common taxonomy classification for MPs; however, still in 2019 Cowger et al. [23] reported 19 different terms for MPs morphology, used differently by various studies in often overlapping subsets $[23,100]$. Moreover, the allotment of sources based on mere taxonomy has been challenged: as an example, fibers, one of the most found items in WWTPs effluents, could have origin in wastewater effluents, but also in atmospheric fallout or in fishing nets decay $[8,101]$. Microbeads also could have origin e.g. in personal care products or air blasting products [69]. Polymers characterization might add some information: the plastic objects marketed need indeed different polymer properties according to their use [102]. An attempt in classification was realized by Wang et al. [101] considering morphology, size and chemical characterization. Eight classes were defined with possible sources (with points given on the probability level of source belonging), and a ninth class as "others" for unidentifiable plastic objects. They also defined a "diversity index" to quantify the variety of MPs sources. These two tools were conceived to help in individuating management strategies based on the variety of the MPs sources hypothesized. This approach was indeed used by Liu et al. [40] to understand and describe MPs pollution sources and distribution in the Haihe river [40]. This classification still leaves some decision to the operator and it is therefore prone to human errors, even if strongly limited by the rules imposed by the method. Therefore, more automated systems should be developed.

The topic of MPs sources individuation and quantification has also already been addressed in literature. Indeed the review by Fahrenfeld et al. [90] deals with the issue of source tracking in freshwater environments and identifies three methods to this purpose: (1) linking particles characteristics to sources, (2) source sampling and mass balance to establish inputs, (3) considering particle surface contaminants to implicate potential sources. Cowger et al. [23] specifically focused on WWTPs as MPs sources, categorized instead MPs water pollution evidences from WWTPs in anecdotal evidence, taxonomic evidence and evidences based on MPs correlation between the effluents and the water body. The correlation was evaluated based on proximity and quantity of WWTPs discharge. Of the 23 studies they reviewed, 11 had the aim of establishing the role of WWTPs as MPs source, only 6 sampled WWTPs effluent too and only 5 did not establish the wastewater effluent to be a significant contributor.

Mass balance would theoretically offer the most reliable results, but various issues must be considered: e.g. mass distribution along a whole section is necessary though not always easily achievable; sampling of different matrices would be appropriate to establish sources and sinks (water, sediments and in some cases even biota) [23]; the lowest size classes appear to be the most common, especially in freshwaters, but their contribution to the whole mass evaluation could be expected to be less relevant [47]. Anyway, to the best knowledge of the authors, no researches have applied this method yet.

Studies on MPs are including more often information on both morphology and chemical characterization. To understand how this information is used to evaluate WWTPs as source of MPs, two cases are here considered: first, where only up-stream and down-stream sections to a WWTP are analysed, and the second one where also the WWTP effluent is considered.

Indeed, as reported by Fahrenfeld et al. [90], and as could be concluded by the previous section of this review, the MPs fingerprint of a WWTP effluent in terms of MPs characteristics is not necessarily foreseen [90].

Aspect of interest should be the definition of what is "upstream" and "downstream" sampling, in terms of distance from the WWTP, waterbody characteristics and WWTP effluent plume. This aspect is also not always clearly reported.

Studies where upstream and downstream sections to WWTPs were purposefully targeted, but WWTPs effluent was not analysed, are reported in Table 5 (ref. 1-9), as the source apportionment strategy. Mostly, source apportionment followed morphology and difference in concentration. Limits on morphology-based attribution have been already discussed in this section. When evaluating MPs concentration difference between upstream and downstream a WWTP, the dilution properties of the waterbody has to be considered; hence, a high load of MPs from a WWTP can be unseen due to missing change in concentration. Also, if the MPs concentration in WWTP effluent and the waterbody is similar, a variation in concentration between up-stream and downstream section is not recorded although the relative contribution of the WWTP to the MPs pollution of the water body could be relevant. Often indeed, as shown in Table 5, the difference is not significant, but the WWTPs are still confirmed as source of MPs to the receiving water body. On the contrary, a significant difference could be linked of course to the higher MPs concentration in the WWTP effluent (if other sources could be excluded or deemed not relevant); however, the scenarios, also 
Table 5

Studies reporting up-stream and down-stream concentration to WWTPs (ref. 1-9), up-stream, down-stream concentration to WWTPs and effluent characterization (ref. 10-17).

\begin{tabular}{|c|c|c|c|c|c|c|}
\hline Ref. & Country & $\begin{array}{l}\text { Water } \\
\text { body }\end{array}$ & Matrix analysed & WWTP capacity & Streamflow & Results and WWTP as source attribution methods \\
\hline 1 & $\mathrm{CA}$ & river & water, sediment & n.a & n.a & $\begin{array}{l}\text { Significant increase of MPs abundance downstream only in one } \\
\text { over ten WWTPs evaluated } \\
\text { No evaluation of apportionment if not based on concentration, (but } \\
\text { environmental predictors based on MPs concentration and } \\
\text { morphology) }\end{array}$ \\
\hline 2 & CHINA & river & water & n.a & $26.4 * 10^{\wedge} 9 \mathrm{~m}^{3} / \mathrm{y}$ & $\begin{array}{l}\text { Different results with different sampling devices, but in } \\
\text { conclusion WWTPs deemed as one of the main discharge sources } \\
\text { of MPs in the river } \\
\text { Evaluation of apportionment based on concentration, (sources on MPs } \\
\text { morphology and chemical characterization) }\end{array}$ \\
\hline 3 & UK & river & water & $10-900 * 10 \wedge 3$ P.E & n.a & $\begin{array}{l}\text { MPs generally increased downstream WWTPs, no variation of MPs } \\
\text { types hence } \\
\text { Evaluation of apportionment based on concentration and morphology }\end{array}$ \\
\hline 4 & GER & river & water & \multicolumn{2}{|c|}{$\begin{array}{l}\text { (Teltow Canal discharge }) /(\text { WWTP effluent })= \\
{[0.65-2.6] \text { during the sampling days }}\end{array}$} & $\begin{array}{l}\text { Significant increase of MPs concentration for one over three } \\
\text { WWTPs considered. No spatial or temporal variation for MPs } \\
\text { shape and size, hence } \\
\text { Evaluation of apportionment based on concentration and morphology }\end{array}$ \\
\hline 5 & $\mathrm{CA}$ & river & water, biota & $\begin{array}{l}200 * 10 \wedge 3 \text { P.E (24.1-77.4*10^3 } \\
\mathrm{mc} / \mathrm{d} \text { during sampling days) }\end{array}$ & n.a & $\begin{array}{l}\text { Higher concentration upstream the WWTP } \\
\text { Evaluation of apportionment based on concentration and morphology }\end{array}$ \\
\hline 6 & USA & river & water & n.a & n.a & $\begin{array}{l}\text { WWTP had no effect on MPs concentration or type } \\
\text { Evaluation of apportionment based on concentration and morphology }\end{array}$ \\
\hline 7 & USA & river & WWTP, water & $\begin{array}{l}\text { WWTPs effluent was } 0-98 \% \text { of } \\
\text { streamflow }\end{array}$ & $(5-185 \mathrm{mc} / \mathrm{s})$ & $\begin{array}{l}\text { No correlation between MPs types and WWTPs, role of WWTPs as } \\
\text { source remains unclear } \\
\text { Evaluation of apportionment based on concentration and morphology }\end{array}$ \\
\hline 8 & USA & river & water & \multicolumn{2}{|c|}{ Contrib. of effluent to flow (\%) [13.17-110.82] } & $\begin{array}{l}\text { MPs concentration higher downstream of } 7 \text { out of nine WWTPs } \\
\text { (two significantly higher) } \\
\text { Evaluation of apportionment based on concentration and morphology } \\
\text { and bacterial communities }\end{array}$ \\
\hline 9 & USA & river & water & $8.69-18.9 * 10^{\wedge} 3 \mathrm{mc} / \mathrm{d}$ & n.a & $\begin{array}{l}\text { Significant increase of MPs downstream of some WWTPs as } \\
\text { function of size class and morphology (I and II MPs) } \\
\text { Evaluation of apportionment based on concentration and morphology } \\
\text { (size class, I and II MPs) }\end{array}$ \\
\hline 10 & NL & River & $\begin{array}{l}\text { WWTP, } \\
\text { river surface water }\end{array}$ & $\begin{array}{l}\text { M } 0.041-3.4 \mathrm{mc} / \mathrm{s} \\
\text { D } 0.53-9.7 \mathrm{mc} / \mathrm{s}\end{array}$ & $\begin{array}{l}\text { Meuse } 350 \mathrm{mc} / \mathrm{s} \\
\text { av } \\
\text { Dommel } 3.1 \mathrm{mc} / \\
\mathrm{s} \text { av }\end{array}$ & $\begin{array}{l}\text { Confirmation of WWTPs as source } \\
\text { No general increase between up and down stream WWTPs } \\
\text { Higher concentration attributed to diffuse sources or other } \\
\text { riverine dynamics and processes } \\
\text { No evaluation of apportionment, if not based on concentration }\end{array}$ \\
\hline 11 & $\mathrm{CA}$ & $\begin{array}{l}\text { Creeks, } \\
\text { lake }\end{array}$ & WWTP, water & n.a & n.a & $\begin{array}{l}\text { Confirmation of WWTPs as "dominant" source } \\
\text { Evaluation of apportionment based on concentration and MP } \\
\text { characterization }\end{array}$ \\
\hline 12 & ES & Lagoons & WWTP, sediments & $207685-929962 \mathrm{~m}^{3} / \mathrm{y}$ authorized & ischarge & $\begin{array}{l}\text { Confirmation of WWTPs as source } \\
\text { Higher MPs concentration in artificially recharged lagoons } \\
\text { Evaluation of apportionment based on concentration and MP } \\
\text { morphology and spectra }\end{array}$ \\
\hline 13 & USA & River & $\begin{array}{l}\text { WWTP, water, } \\
\text { sediment, air }\end{array}$ & n.a & n.a & $\begin{array}{l}\text { Confirmation of WWTPs as source } \\
\text { No significant increase up and downstream WWTP } \\
\text { Study focused on microfibers } \\
\text { Other sources or reservoirs of synthetic microfibers suggested } \\
\text { No evaluation of apportionment, if not based on concentration }\end{array}$ \\
\hline 14 & CHINA & River & $\begin{array}{l}\text { WWTP, water } \\
\text { sediment }\end{array}$ & $0.55-1.2 * 10^{\wedge} 6 \mathrm{mc} / \mathrm{d}$ & n.a & $\begin{array}{l}\text { Confirmation of WWTPs as source } \\
\text { No significant relation between MPs pollution in urban river and } \\
\text { the geographical location of the WWTPs } \\
\text { No evaluation of apportionment, if not based on concentration }\end{array}$ \\
\hline 15 & CA & River & Water, sediments & n.a & n.a & $\begin{array}{l}\text { Confirmation of WWTPs as source } \\
\text { MPs concentration significantly higher downstream WWTPs than } \\
\text { upstream } \\
\text { No evaluation of apportionment, if not based on concentration }\end{array}$ \\
\hline 16 & FR & River & $\begin{array}{l}\text { WWTP, water, atm } \\
\text { fallout }\end{array}$ & n.a & n.a & $\begin{array}{l}\text { Confirmation of WWTPs as source } \\
\text { MPs. A subsequent study deepened these aspects but focused only } \\
\text { on the fibers class. } \\
\text { No evaluation of apportionment, if not based on concentration }\end{array}$ \\
\hline 17 & NL & River, sea & $\begin{array}{l}\text { WWTP Water, } \\
\text { sediments, biota }\end{array}$ & $\begin{array}{l}385-30000 \mathrm{~m}^{3} / \mathrm{h} \\
\text { Dry weather flow }\end{array}$ & n.a & $\begin{array}{l}\text { Confirmation of WWTPs as source } \\
\text { No evidence of dilution for effluent MPs, hence the presence of } \\
\text { many diffuse sources of MPs is suggested } \\
\text { No evaluation of apportionment, if not based on concentration }\end{array}$ \\
\hline
\end{tabular}

Ref. 1 [29], 2 [40], 3 [103], 4 [104], 5 [105], 6 [106], 7 [107], 8 [108], 9 [109], 10 [47], 11 [44], 12 [30], 13 [110], 14 [111], 15 [112], 16 [113], 17 [114] n.a not available. 
from an environmental management point of view, are different according to the relative flow of the effluent. From a local point of view, this is of paramount importance to establish where to direct the efforts in reducing MPs pollutions and their possible outcome. Moreover, if the concentration of MPs in the water body is always reported, that is not the same for WWTPs volume discharge and river flow, which instead is needed for a proper evaluation of relative contribution to MPs pollution. MPs concentration is indeed the key parameter for toxicology and risk analysis, but it is not enough for the beginning of MPs pollution control strategy.

Gaining the information on WWTPs effluent characterization in terms of MPs seems not to suffice to a proper source apportionment and relative role evaluation either. Indeed, as shown in the records 10-17 of Table 5, main apportionment strategy is still based on concentration difference. The analysis of the WWTP effluent is indeed mostly used only to confirm the MPs source and not to establish more definite certainties on relative contribution.

Moreover, another relevant aspect linked to WWTPs role in MPs pollution is the possible change not only in MPs concentration but also in MPs characteristics distribution. Size, shapes, colour and chemical composition are indeed all factors influencing the biota uptake [115, 116].

Indeed, some studies noticed even statistically significant changes in distribution between upstream and downstream sections to WWTPs [108,109]. Moreover, Grbić et al. [44] using nMDS (non-metric multidimensional scaling) plots found non-existent grouping based on chemical classification, while for categories and colour/categories the lake surface MPs pollution grouped first with agricultural runoff and next with stormwater runoff. Instead, Baldwin et al. [107] observed that no plastic types were correlated with the WWTPs effluent contribution to the streamflow. Hylton and Ghezzi [106] noticed no effects of WWTPs on particle types (or abundance) and Lin et al. [111] did not observed influence of WWTPs geographical location on MPs pollution.

Worth mentioning is also the study by Uurasjärvi et al. [117] where proximity, taxonomy and chemical characterization were investigated in a northern European lake. They found the highest amount of MPs close to the effluent of a WWTP and with the typical characteristics of synthetic clothes release [117]. Colours and chemical composition were considered determinant to attribute the origin of fibers to fishing nets and ropes by Migwi et al. [35] in lake Naivasha. A mention is also to be given to studies like the one by Zhang et al. [32] where the WWTPs effluent was thoughtfully characterized; however, there was no analysis of upstream sections and hence the data were used only for an evaluation of daily discharges as a confirmation of WWTPs as source.

In conclusions, WWTPs are undoubtfully a source of MPs to freshwaters systems, their relevance though is highly locally dependent. MPs concentration is the key parameter for the related environmental risk assessment, and hence rightfully the factor mostly studied; however, to evaluate the better management solutions to the MPs pollution, the role of WWTPs in terms of relative loads has to be deepen more. It cannot also be overseen the possible changes in MPs distribution in the waterbody, linked to the WWTPs effluent discharge, considering the relevance of factors such as shape, size and colour in biota uptake.

\section{MPs in the urban water cycle}

The hydrological water cycle is defined as " $a$ conceptual model describing the storage and circulation of water between the biosphere, atmosphere, lithosphere and the hydrosphere" [118]. Storage compartments are the atmosphere, oceans, lakes, rivers, streams, soils, glaciers, snowfields and groundwater aquifers. Processes leading to circulation are: evapotranspiration, condensation, precipitation, infiltration, percolation, snowmelt and runoff, also called the "water cycle components" [118]. All the components and storage compartments are present in the urban water cycle but modified in their relative effect by urbanization; complexity is added to the hydrological cycle by anthropogenic interventions. Elements added to the systems are mainly the water supply chain and the water sanitation systems, including stormwater management. In this review, the information on MPs in the main sections of the urban water cycle have been examined and, in this section, the main conclusions are summed up for a complete overview. Regarding the water supply chain, MPs have been extensively found in surface waters and have been fully characterized in terms of size, colour, shape and chemical constituents. However, the determination of sources, their relative contribution and the influence of the socio-economic factors and hydrological features of the catchments, remain a local information due to the absence of analytical protocol standardization, lacking anyhow in quantification and certainty. Groundwater sources have been instead less explored, though the few information available confirm their pollution due to also MPs. The water supply chain is supposed to be responsible of MPs contamination to a certain extent, but more tests are needed to generalize such an assessment. Drinking water treatment plants remove MPs with different results depending on plant layout and water sources, though the evidences are once again too scant to generalize. The influence of operational parameters on the removal efficiency of the various units is still mostly unknown. Presence of MPs in drinking water and beverages have been extensively demonstrated, though the effects of their ingestion by humans are still to be understood. Used water ending up in the wastewater collecting systems are enriched in MPs by households and industries; moreover, stormwaters have been proved to be contaminated by secondary MPs of various genera, such as from tires wear. Influent to wastewater treatments are indeed confirmed to be heavily polluted by MPs, while time related patterns and MPs distribution characteristics need more research. Wastewater treatment plants have been extensively studied in regard to MPs, but still not enough information have been gathered on the influence of operational parameters, processes influencing MPs removal and distribution, effect of the treatment on MPs fragmentation; this scarce knowledge is still due to the ever-present lack of method standardization. MPs have been recorded also in WWTPs effluents and sludge and are hence spread into the environment through sludge application in agriculture, water reuse for irrigation and water discharge in the receiving waterbody, hence possibly back to a water source. Moreover, also the atmospheric compartment has been checked positively for MPs pollution, becoming another source due to deposition and fallout.

Considering the whole cycle, MPs can be therefore considered ubiquitous. The MPs presence in the water cycle cannot be defined as "closed". New MPs are indeed steadily introduced and formed in the system. The continuous feed by human activities, specifically by urban areas and industries is indeed confirmed, even if its relative contribution to an already polluted environment is not easily accounted. Fragmentation is also another source of MPs generation within the cycle, occurring both in natural environments and anthropic, e.g. in the water treatment plants. Atmospheric deposition is now considered a significant reality and it is possible the resuspension of MPs from dry surfaces or even from the water surface by wave breaking and bursting bubbles [9]. Besides, it is likely the MPs sinking with sediments or circling within the water bodies. Sediments are also possibly resuspended in rivers due to flow regime changes, but ultimately MPs will end up trapped on the bottom floor elsewhere or fragmented in the tiniest pieces. Indeed, for example, deep sea sediments might be considered as a sink for MPs [119], but according to MPs characteristics and from what seen so far, the same might stand for both river beds and lakes bottom. It is also confirmed the accumulation of MPs in soils treated with WWTPs sludge, with eventually a further transportation elsewhere by runoff. MPs pollution is pervasive, always introduced and generated within the cycle, with effects on each compartment due to transport processes, both natural or modified by the anthropic manufactures (e.g. those present in urban areas, water supply chain, wastewater collecting systems and water treatment plants included): it is clear how, to be properly addressed, it needs to be considered in its whole and not as a phenomenon restricted to separated sections. To do so, coherent description of 
MPs among the different compartments is needed. An interesting starting point in such a direction could be the approach designed by Kooi et al. [120] where MPs are described by a 3D continuous probability distribution, with size, density and shape as dimensions. Description of MPs by continuous values while depicting simultaneously the three main attributes (shape, size, density) allows indeed the representation of the true complexity of the objects [120]. Moreover, the definition of shapes based on the Corey shape factor reduces the uncertainties in classifications [120]. Furthermore, this approach, by exploiting the difference among distributions, might open new relevant insights on the relationships between sources and the environmental pollution by MPs, as on the processes active, the effects and efficiencies of water treatment.

\section{Conclusions and future perspectives}

MPs presence has been documented in all urban water cycle compartments. However, the level of knowledge is still not even, with less information available for groundwaters and the drinking water supply chain. MPs temporal or weather-related patterns have been detected, but not always confirmed: hence a deeper knowledge of this aspect is also recommended. The same stands for the influence of the environmental and socio-economic aspects of the area on the MPs abundance in the various compartments of the urban water cycle. This issue has been indeed often considered, but the information retrieved are still strongly linked to the local level and can be hardly generalized.

Regarding water treatments, MPs are not removed but only retained, possibly fragmented and concentrated in the sludge. Different MPs classes appear also not to be evenly removed by the treatments, with preferences for specific size or shape according to the operational units or technology involved. The processes and the aspects influencing such a behavior still need clearance

The lower size classes are the one to put under the spotlight: they are often the most common, in environmental compartments too, and apparently the hardest to be removed. The smallest particles are also possibly the most dangerous.

With the aim of MPs pollution control through point barriers such as WWTPs and DWTPs, the following answers must be provided for the immediate future: how the operational units of water treatments (DWTPS or WWTPs) change the MPs distribution in the treated flow; how the WWTPs effluent load change the MPs distribution in the receiving waterbody.

Mostly important, it still has to be defined the requested level of MPs removal by a WWTP or DWTP, and hence the possible need of more efficient solutions, such as membrane processes. In this regard, a risk assessment based on the PNEC (Predicted No Effect Concentration) should represent the best approach, like it also has been done for other types of contaminants. The toxicological knowledge advancements are hence to be carefully revised to obtain more refined data on such aspects and allow for more reliable results. It is hence clear the need of further advancements on these aspects in parallel to the research on MPs presence in the environment.

Moreover, standardization and coherence of protocols is of utmost relevance for a true advancement in MPs pollution knowledge. In this regard, a contribution could be the verification, deepening and widening of the chances offered by changing the approach to MPs reports: continuous description to overcome the limits imposed by discrete MPs classification.

\section{Funding}

This research did not receive any specific grant from funding agencies. in the public, commercial, or not-for-profit sectors

\section{Declaration of Competing Interest}

The authors declare that they have no known competing financial interests or personal relationships that could have appeared to influence the work reported in this paper.

\section{Appendix A. Supplementary data}

Supplementary material related to this article can be found, in the online version, at doi:https://doi.org/10.1016/j.jwpe.2020.101787.

\section{References}

[1] R. Geyer, J.R. Jambeck, K.L. Law, Production, use, and fate of all plastics ever made, Sci. Adv. 3 (2017) 25-29, https://doi.org/10.1126/sciadv.1700782.

[2] J.-L. Xu, K.V. Thomas, Z. Luo, A.A. Gowen, FTIR and Raman imaging for microplastics analysis: state of the art, challenges and prospects, TrAC Trends Anal. Chem. 119 (2019) 115629, https://doi.org/10.1016/j.trac.2019.115629.

[3] M. Enfrin, L.F. Dumée, J. Lee, Nano/microplastics in water and wastewater treatment processes - origin, impact and potential solutions, Water Res. 161 (2019) 621-638, https://doi.org/10.1016/j.watres.2019.06.049.

[4] A.A. Horton, A. Walton, D.J. Spurgeon, E. Lahive, C. Svendsen, Microplastics in freshwater and terrestrial environments: evaluating the current understanding to identify the knowledge gaps and future research priorities, Sci. Total Environ. 586 (2017) 127-141, https://doi.org/10.1016/j.scitotenv.2017.01.190.

[5] M. Cole, P. Lindeque, C. Halsband, T.S. Galloway, Microplastics as contaminants in the marine environment: a review, Mar. Pollut. Bull. 62 (2011) 2588-2597, https://doi.org/10.1016/j.marpolbul.2011.09.025.

[6] M. Wagner, S. Lambert, Freshwater Microplastics, The Handbo, Springer Nature, 2018, https://doi.org/10.1007/978-3-319-61615-5.

[7] J.P. Da Costa, A. Paço, P.S.M. Santos, A.C. Duarte, T. Rocha-Santos, Microplastics in soils: assessment, analytics and risks, Environ. Chem. 16 (2019) 18-30, https://doi.org/10.1071/EN18150.

[8] R. Dris, J. Gasperi, M. Saad, C. Mirande, B. Tassin, Synthetic fibers in atmospheric fallout: A source of microplastics in the environment? Mar. Pollut. Bull. 104 (2016) 290-293, https://doi.org/10.1016/j.marpolbul.2016.01.006.

[9] S.L. Wright, J. Ulke, A. Font, K.L.A. Chan, F.J. Kelly, Atmospheric microplastic deposition in an urban environment and an evaluation of transport, Environ. Int. 136 (2020) 105411, https://doi.org/10.1016/j.envint.2019.105411.

[10] M.A. Nadal, C. Alomar, S. Deudero, High levels of microplastic ingestion by the semipelagic fish bogue Boops boops (L.) around the Balearic Islands, Environ. Pollut. 214 (2016) 517-523, https://doi.org/10.1016/j.envpol.2016.04.054.

[11] J. Li, C. Green, A. Reynolds, H. Shi, J.M. Rotchell, Microplastics in mussels sampled from coastal waters and supermarkets in the United Kingdom, Environ. Pollut. 241 (2018) 35-44, https://doi.org/10.1016/j.envpol.2018.05.038.

[12] GESAMP, Sources, fate and effects of MP in the marine environment, J. Ser. GESAMP Reports Stud. 90 (2015) 98. www.imo.org.

[13] M. Lares, M.C. Ncibi, M.M. Sillanpää, M.M. Sillanpää, Occurrence, identification and removal of microplastic particles and fibers in conventional activated sludge process and advanced MBR technology, Water Res. 133 (2018) 236-246, https:// doi.org/10.1016/j.watres.2018.01.049.

[14] F. Corami, B. Rosso, B. Bravo, A. Gambaro, C. Barbante, A novel method for purification, quantitative analysis and characterization of microplastic fibers using Micro-FTIR, Chemosphere 238 (2020) 124564, https://doi.org/10.1016/j. chemosphere.2019.124564.

[15] ECHA, Note on Substance Identification and the Potential Scope of a Restriction on Uses of "microplastics,", 2018, p. 13. https://echa.europa.eu/-/stakeholderworkshop-on-microplastic-particles.

[16] J.P.G.L. Frias, R. Nash, Microplastics: Finding a consensus on the definition, Mar. Pollut. Bull. 138 (2019) 145-147, https://doi.org/10.1016/j. marpolbul.2018.11.022.

[17] SAPEA, A scientific perspective on microplastics in nature and society, SAPEA (2019).

[18] R. Triebskorn, T. Braunbeck, T. Grummt, L. Hanslik, S. Huppertsberg, M. Jekel, T. P. Knepper, S. Krais, Y.K. Müller, M. Pittroff, A.S. Ruhl, H. Schmieg, C. Schür, C. Strobel, M. Wagner, N. Zumbülte, H.R. Köhler, Relevance of nano- and microplastics for freshwater ecosystems: a critical review, TrAC - Trends Anal. Chem. 110 (2019) 375-392, https://doi.org/10.1016/j.trac.2018.11.023.

[19] World Health Organization, Microplastics in Drinking Water, Geneva, 2019.

[20] Committee on the Environment Public Health and Food Safety, European Parliament, Provisional Agreement Resulting from Interinstitutional Negotiations, 2019, pp. 1-72.

[21] Scientific Advice Mechanism Unit of the European Commission, Environmental and Health Riskd of Microplastics Pollution, 2019, https://doi.org/10.2777/ 54199.

[22] European Commission, Evaluation of the Urban Waste Water Treatment Directive, 2019, p. 186, environment/water/water-urbanwaste/pdf/UWWTD Evaluation SWD 448-701 web.pdf. https://ec.europa.eu/.

[23] W. Cowger, A.B. Gray, M. Eriksen, C. Moore, M. Thiel, Chapter 8 evaluating wastewater effluent as a source of microplastics in environmental samples. Microplastics in Water and Wastewater, 2019, pp. 109-131, https://doi.org/ 10.2166/9781789060034_0109.

[24] S. Galafassi, L. Nizzetto, P. Volta, Plastic sources: a survey across scientific and grey literature for their inventory and relative contribution to microplastics pollution in natural environments, with an emphasis on surface water, Sci. Total Environ. 693 (2019) 133499, https://doi.org/10.1016/j.scitotenv.2019.07.305. 
[25] J.K.H. Wong, K.K. Lee, K.H.D. Tang, P.S. Yap, Microplastics in the freshwater and terrestrial environments: prevalence, fates, impacts and sustainable solutions, Sci. Total Environ. 719 (2020) 137512, https://doi.org/10.1016/j. scitotenv.2020.137512.

[26] L.M. Rios Mendoza, M. Balcer, Microplastics in Freshwater Environments, Elsevier Inc., 2020, https://doi.org/10.1016/b978-0-12-409548-9.12394-2.

[27] T. Schell, A. Rico, M. Vighi, Occurrence, fate and fluxes of plastics and microplastics in terrestrial and freshwater ecosystems, Rev. Environ. Contam. Toxicol. 238 (2020) 22-28, https://doi.org/10.1007/398.

[28] C. Li, R. Busquets, L.C. Campos, Assessment of microplastics in freshwater systems: a review, Sci. Total Environ. 707 (2019) 135578, https://doi.org/ 10.1016/j.scitotenv.2019.135578.

[29] A. Crew, I. Gregory-Eaves, A. Ricciardi, Distribution, abundance, and diversity of microplastics in the upper St. Lawrence River, Environ. Pollut. 260 (2020) 113994, https://doi.org/10.1016/j.envpol.2020.113994.

[30] C. Edo, M. González-Pleiter, M. Tamayo-Belda, F.E. Ortega-Ojeda, F. Leganés, F. Fernández-Piñas, R. Rosal, Microplastics in sediments of artificially recharged lagoons: case study in a Biosphere Reserve, Sci. Total Environ. 729 (2020) 138824, https://doi.org/10.1016/j.scitotenv.2020.138824.

[31] Q. Xu, R. Xing, M. Sun, Y. Gao, L. An, Microplastics in sediments from an interconnected river-estuary region, Sci. Total Environ. 729 (2020) 139025, https://doi.org/10.1016/J.SCITOTENV.2020.139025.

[32] L. Zhang, J. Liu, Y. Xie, S. Zhong, B. Yang, D. Lu, Q. Zhong, Distribution of microplastics in surface water and sediments of Qin river in Beibu Gulf, China, Sci. Total Environ. 708 (2020) 135176, https://doi.org/10.1016/j. scitotenv. 2019.135176.

[33] Y. Huang, M. Tian, F. Jin, M. Chen, Z. Liu, S. He, F. Li, L. Yang, C. Fang, J. Mu, Coupled effects of urbanization level and dam on microplastics in surface water in a coastal watershed of Southeast China, Mar. Pollut. Bull. 154 (2020) 111089, https://doi.org/10.1016/j.marpolbul.2020.111089.

[34] H.T.J. Dahms, G.J. van Rensburg, R. Greenfield, The microplastic profile of an urban African stream, Sci. Total Environ. 731 (2020), https://doi.org/10.1016/j scitotenv.2020.138893.

[35] F.K. Migwi, J.A. Ogunah, J.M. Kiratu, Occurrence and spatial distribution of microplastics in the surface waters of Lake Naivasha, Kenya, Environ. Toxicol. Chem. 39 (2020) 765-774, https://doi.org/10.1002/etc.4677.

[36] P. Lestari, Y. Trihadiningrum, B.A. Wijaya, K.A. Yunus, M. Firdaus, Distribution of microplastics in Surabaya River, Indonesia, Sci. Total Environ. 726 (2020) 138560, https://doi.org/10.1016/j.scitotenv.2020.138560.

37] P.L. Corcoran, S.L. Belontz, K. Ryan, M.J. Walzak, Factors controlling the distribution of microplastic particles in benthic sediment of the Thames River, Canada, Environ. Sci. Technol. 54 (2020) 818-825, https://doi.org/10.1021/acs. est.9b04896.

[38] M. Constant, W. Ludwig, P. Kerhervé, J. Sola, B. Charrière, A. Sanchez-Vidal, M. Canals, S. Heussner, Microplastic fluxes in a large and a small Mediterranean river catchments: the Têt and the Rhône, Northwestern Mediterranean Sea, Sci. Total Environ. 716 (2020), https://doi.org/10.1016/j.scitotenv.2020.136984.

[39] T. Stanton, M. Johnson, P. Nathanail, W. MacNaughtan, R.L. Gomes, Freshwate microplastic concentrations vary through both space and time, Environ. Pollut. 263 (2020) 114481, https://doi.org/10.1016/j.envpol.2020.114481.

[40] Y. Liu, J. Di Zhang, C.Y. Cai, Y. He, L.Y. Chen, X. Xiong, H.J. Huang, S. Tao, W. $X$. Liu, Occurrence and characteristics of microplastics in the Haihe River: an investigation of a seagoing river flowing through a megacity in northern China, Environ. Pollut. 262 (2020) 114261, https://doi.org/10.1016/j. envpol.2020.114261.

[41] G. Wong, L. Löwemark, A. Kunz, Microplastic pollution of the Tamsui River and its tributaries in northern Taiwan: spatial heterogeneity and correlation with precipitation, Environ. Pollut. 260 (2020) 113935, https://doi.org/10.1016/j envpol.2020.113935.

[42] L. Zuo, Y. Sun, H. Li, Y. Hu, L. Lin, J. Peng, X. Xu, Microplastics in mangrove sediments of the Pearl River Estuary, South China: correlation with halogenated flame retardants' levels, Sci. Total Environ. 725 (2020) 138344, https://doi.org/ 10.1016/j.scitotenv.2020.138344.

[43] P. Wu, Y. Tang, M. Dang, S. Wang, H. Jin, Y. Liu, H. Jing, C. Zheng, S. Yi, Z. Cai, Spatial-temporal distribution of microplastics in surface water and sediments of Maozhou River within Guangdong-Hong Kong-Macao Greater Bay Area, Sci. Total Environ. 717 (2020) 135187, https://doi.org/10.1016/j.scitotenv.2019.135187.

[44] J. Grbić, P. Helm, S. Athey, C.M. Rochman, Microplastics entering northwester Lake Ontario are diverse and linked to urban sources, Water Res. 174 (2020), https://doi.org/10.1016/j.watres.2020.115623.

[45] G. Wang, J. Lu, Y. Tong, Z. Liu, H. Zhou, N. Xiayihazi, Occurrence and pollution characteristics of microplastics in surface water of the Manas River Basin, China, Sci. Total Environ. 710 (2020) 136099, https://doi.org/10.1016/j. scitotenv.2019.136099.

[46] M. Han, X. Niu, M. Tang, B.T. Zhang, G. Wang, W. Yue, X. Kong, J. Zhu, Distribution of microplastics in surface water of the lower Yellow River near estuary, Sci. Total Environ. 707 (2020) 135601, https://doi.org/10.1016/j. scitotenv.2019.135601.

[47] S.M. Mintenig, M. Kooi, M.W. Erich, S. Primpke, P.E. Redondo- Hasselerharm, S. C. Dekker, A.A. Koelmans, A.P. van Wezel, A systems approach to understand microplastic occurrence and variability in Dutch riverine surface waters, Water Res. 176 (2020) 115723, https://doi.org/10.1016/j.watres.2020.115723.

[48] S.V. Panno, W.R. Kelly, J. Scott, W. Zheng, R.E. McNeish, N. Holm, T.J. Hoellein, E.L. Baranski, Microplastic Contamination in Karst Groundwater Systems, Groundwater 57 (2019) 189-196, https://doi.org/10.1111/gwat.12862.
[49] S.M. Mintenig, M.G.J. Löder, S. Primpke, G. Gerdts, Low numbers of microplastics detected in drinking water from ground water sources, Sci. Total Environ. 648 (2019) 631-635, https://doi.org/10.1016/j.scitotenv.2018.08.178.

[50] M. Ganesan, G. Nallathambi, S. Srinivasalu, Fate and transport of microplastics from water sources, Curr. Sci. 117 (2019) 1874-1879, https://doi.org/10.18520/ cs/v117/i11/1874-1879.

[51] V. Re, Shedding light on the invisible: addressing the potential for groundwater contamination by plastic microfibers, Hydrogeol. J. 27 (2019) 2719-2727, https://doi.org/10.1007/s10040-019-01998-x.

[52] M. Kosuth, S.A. Mason, E.V. Wattenberg, Anthropogenic contamination of tap water, beer, and sea salt, PLoS One 13 (2018) 1-18, https://doi.org/10.1371/ journal.pone.0194970.

[53] D. Schymanski, C. Goldbeck, H.U. Humpf, P. Fürst, Analysis of microplastics in water by micro-Raman spectroscopy: release of plastic particles from different packaging into mineral water, Water Res. 129 (2018) 154-162, https://doi.org/ 10.1016/j.watres.2017.11.011.

[54] M. Pivokonsky, L. Cermakova, K. Novotna, P. Peer, T. Cajthaml, V. Janda, Occurrence of microplastics in raw and treated drinking water, Sci. Total Environ. 643 (2018) 1644-1651, https://doi.org/10.1016/j.scitotenv.2018.08.102.

[55] B.E. Oßmann, G. Sarau, H. Holtmannspötter, M. Pischetsrieder, S.H. Christiansen, W. Dicke, Small-sized microplastics and pigmented particles in bottled mineral water, Water Res. 141 (2018) 307-316, https://doi.org/10.1016/j. watres.2018.05.027.

[56] S.A. Mason, V.G. Welch, J. Neratko, Synthetic polymer contamination in bottled water, Front. Chem. 6 (2018), https://doi.org/10.3389/fchem.2018.00407.

[57] A.A. Koelmans, N.H. Mohamed Nor, E. Hermsen, M. Kooi, S.M. Mintenig, J. De France, Microplastics in freshwaters and drinking water: critical review and assessment of data quality, Water Res. 155 (2019) 410-422, https://doi.org/ 10.1016/j.watres.2019.02.054

[58] D. Eerkes-Medrano, H.A. Leslie, B. Quinn, Microplastics in drinking water: a review and assessment, Curr. Opin. Environ. Sci. Heal. Heal. 7 (2019) 69-75, https://doi.org/10.1016/j.coesh.2018.12.001.

[59] R. Akhbarizadeh, S. Dobaradaran, T.C. Schmidt, I. Nabipour, J. Spitz, Worldwide bottled water occurrence of emerging contaminants: a review of the recent scientific literature, J. Hazard. Mater. 392 (2020) 122271, https://doi.org/ 10.1016/j.jhazmat.2020.122271.

[60] K. Novotna, L. Cermakova, L. Pivokonska, T. Cajthaml, M. Pivokonsky, Microplastics in drinking water treatment - current knowledge and research needs, Sci. Total Environ. 667 (2019) 730-740, https://doi.org/10.1016/j. scitotenv. 2019.02.431.

[61] M. Shen, B. Song, Y. Zhu, G. Zeng, Y. Zhang, Y. Yang, X. Wen, M. Chen, H. Yi, Removal of microplastics via drinking water treatment: current knowledge and future directions, Chemosphere 251 (2020) 126612, https://doi.org/10.1016/j chemosphere.2020.126612.

[62] Z. Wang, T. Lin, W. Chen, Occurrence and removal of microplastics in an advanced drinking water treatment plant (ADWTP), Sci. Total Environ. 700 (2020) 134520, https://doi.org/10.1016/j.scitotenv.2019.134520.

[63] B. Ma, W. Xue, C. Hu, H. Liu, J. Qu, L. Li, Characteristics of microplastic removal via coagulation and ultrafiltration during drinking water treatment, Chem. Eng. J. 359 (2019) 159-167, https://doi.org/10.1016/j.cej.2018.11.155.

[64] Y. Zhang, A. Diehl, A. Lewandowski, K. Gopalakrishnan, T. Baker, Removal efficiency of micro- and nanoplastics $(180 \mathrm{~nm}-125 \mu \mathrm{m})$ during drinking water treatment, Sci. Total Environ. 720 (2020) 137383, https://doi.org/10.1016/j. scitotenv.2020.137383.

[65] M. Enfrin, J. Lee, P. Le-clech, L.F. Dum, Kinetic and mechanistic aspects of ultrafiltration membrane fouling by nano- and microplastics, J. Memb. Sci. 601 (2020), https://doi.org/10.1016/j.memsci.2020.117890.

[66] V.P. Kelkar, C.B. Rolsky, A. Pant, M.D. Green, S. Tongay, R.U. Halden, Chemical and physical changes of microplastics during sterilization by chlorination, Water Res. 163 (2019) 114871, https://doi.org/10.1016/j.watres.2019.114871.

67] J. Sun, X. Dai, Q. Wang, M.C.M. van Loosdrecht, B.J. Ni, Microplastics in wastewater treatment plants: detection, occurrence and removal, Water Res. (2019) 21-37, https://doi.org/10.1016/j.watres.2018.12.050.

[68] J.C. Prata, Microplastics in wastewater: state of the knowledge on sources, fate and solutions, Mar. Pollut. Bull. 129 (2018) 262-265, https://doi.org/10.1016/j. marpolbul.2018.02.046.

[69] P.L. Ngo, B.K. Pramanik, K. Shah, R. Roychand, P. Linh, B. Kumar, K. Shah, R. Roychand, Pathway, classification and removal efficiency of microplastics in wastewater treatment plants, Environ. Pollut. 255 (2019), https://doi.org/ 10.1016/j.envpol.2019.113326.

[70] Z. Long, Z. Pan, W. Wang, J. Ren, X. Yu, L. Lin, H. Lin, H. Chen, X. Jin, Microplastic abundance, characteristics, and removal in wastewater treatment plants in a coastal city of China, Water Res. 155 (2019) 255-265, https://doi.org/ 10.1016/j.watres.2019.02.028.

[71] P. He, L. Chen, L. Shao, H. Zhang, F. Lü, Municipal solid waste (MSW)landfill: a source of microplastics? -Evidence of microplastics in landfill leachate, Water Res. 159 (2019) 38-45, https://doi.org/10.1016/j.watres.2019.04.060.

[72] F. Liu, K.B. Olesen, A.R. Borregaard, J. Vollertsen, Microplastics in urban and highway stormwater retention ponds, Sci. Total Environ. 671 (2019) 992-1000, https://doi.org/10.1016/j.scitotenv.2019.03.416.

[73] S.A. Carr, J. Thompson, Chapter 4 microplastics : transport and removal at wastewater treatment plants. Microplastics in Water and Wastewater, 2019.

[74] C. Bretas Alvim, J.A. Mendoza-Roca, A. Bes-Piá, Wastewater treatment plant as microplastics release source - quantification and identification techniques, J. Environ. Manage. 255 (2020), https://doi.org/10.1016/j. jenvman.2019.109739. 
[75] A.L. Lusher, R.R. Hurley, C. Vogelsang, Chapter 6 microplastics in sewage sludge: captured but released? Microplastics in Water and Wastewater (2019) 85-100.

[76] C. Rolsky, V. Kelkar, E. Driver, R.U. Halden, Municipal sewage sludge as a source of microplastics in the environment, Curr. Opin. Environ. Sci. Heal. 14 (2020) 16-22, https://doi.org/10.1016/j.coesh.2019.12.001.

[77] Q.T. Birch, P.M. Potter, P.X. Pinto, D.D. Dionysiou, S.R. Al-Abed, Sources, Transport, Measurement and Impact of Nano and Microplastics in Urban Watersheds, Springer, Netherlands, 2020, https://doi.org/10.1007/s11157-02009529-x.

[78] M. Simon, N. van Alst, J. Vollertsen, Quantification of microplastic mass and removal rates at wastewater treatment plants applying Focal Plane Array (FPA) based Fourier Transform Infrared (FT-IR) imaging, Water Res. 142 (2018) 1-9, https://doi.org/10.1016/j.watres.2018.05.019.

[79] C. Akarsu, H. Kumbur, K. Gökdağ, A.E. Kıdeyş, A. Sanchez-Vidal, Microplastics composition and load from three wastewater treatment plants discharging into Mersin Bay, north eastern Mediterranean Sea, Mar. Pollut. Bull. 150 (2020) 110776, https://doi.org/10.1016/j.marpolbul.2019.110776.

[80] S.A. Carr, J. Liu, A.G. Tesoro, Transport and fate of microplastic particles in wastewater treatment plants, Water Res. 91 (2016) 174-182, https://doi.org/ 10.1016/j.watres.2016.01.002.

[81] S.A. Mason, D. Garneau, R. Sutton, Y. Chu, K. Ehmann, J. Barnes, P. Fink, D. Papazissimos, D.L. Rogers, Microplastic pollution is widely detected in US municipal wastewater treatment plant effluent, Environ. Pollut. 218 (2016) 1045-1054, https://doi.org/10.1016/j.envpol.2016.08.056.

[82] H.J. Park, M.J. Oh, P.G. Kim, G. Kim, D.H. Jeong, B.K. Ju, W.S. Lee, H.M. Chung, H.J. Kang, J.H. Kwon, National reconnaissance survey of microplastics in municipal wastewater treatment plants in Korea, Environ. Sci. Technol. 54 (2020) 1503-1512, https://doi.org/10.1021/acs.est.9b04929.

[83] K. Conley, A. Clum, J. Deepe, H. Lane, B. Beckingham, Wastewater treatment plants as a source of microplastics to an urban estuary: removal efficiencies and loading per capita over one year, Water Res. X. 3 (2019) 100030, https://doi.org/ 10.1016/j.wroa.2019.100030.

[84] S. Gündoğdu, C. Cevik, E. Güzel, S. Kilercioğlu, Microplastics in municipal wastewater treatment plants in Turkey: a comparison of the influent and secondary effluent concentrations, Environ. Monit. Assess. 190 (2018), https:// doi.org/10.1007/s10661-018-7010-y.

[85] J. Bayo, S. Olmos, J. López-Castellanos, Microplastics in an urban wastewate treatment plant: the influence of physicochemical parameters and environmental factors, Chemosphere 238 (2020) 124593, https://doi.org/10.1016/j chemosphere.2019.124593.

[86] J. Bayo, J. López-Castellanos, S. Olmos, Membrane bioreactor and rapid sand filtration for the removal of microplastics in an urban wastewater treatment plant, Mar. Pollut. Bull. 156 (2020) 111211, https://doi.org/10.1016/j. marpolbul.2020.111211.

[87] R.M. Blair, S. Waldron, C. Gauchotte-Lindsay, Average daily flow of microplastic through a tertiary wastewater treatment plant over a ten-month period, Water Res. 163 (2019) 114909, https://doi.org/10.1016/j.watres.2019.114909.

[88] O. Mallow, S. Spacek, T. Schwarzböck, J. Fellner, H. Rechberger, A new thermoanalytical method for the quantification of microplastics in industrial wastewater, Environ. Pollut. 259 (2020), https://doi.org/10.1016/j. envpol.2019.113862.

[89] S. Raju, M. Carbery, A. Kuttykattil, K. Senthirajah, A. Lundmark, Z. Rogers, S. SCB, G. Evans, T. Palanisami, Improved methodology to determine the fate and transport of microplastics in a secondary wastewater treatment plant, Water Res. 173 (2020) 115549, https://doi.org/10.1016/j.watres.2020.115549.

[90] N.L. Fahrenfeld, G. Arbuckle-Keil, N. Naderi Beni, S.L. Bartelt-Hunt, Source tracking microplastics in the freshwater environment, TrAC - Trends Anal. Chem. 112 (2019) 248-254, https://doi.org/10.1016/j.trac.2018.11.030.

[91] X. Xu, Y. Jian, Y. Xue, Q. Hou, L.P. Wang, Microplastics in the wastewater treatment plants (WWTPs): occurrence and removal, Chemosphere 235 (2019) 1089-1096, https://doi.org/10.1016/j.chemosphere.2019.06.197.

[92] C. Edo, M. González-Pleiter, F. Leganés, F. Fernández-Piñas, R. Rosal, Fate of microplastics in wastewater treatment plants and their environmental dispersion with effluent and sludge, Environ. Pollut. 259 (2020) 113837, https://doi.org/ 10.1016/j.envpol.2019.113837.

[93] S. Freeman, A.M. Booth, I. Sabbah, R. Tiller, J. Dierking, K. Klun, A. Rotter E. Ben-David, J. Javidpour, D.L. Angel, Between source and sea: the role of wastewater treatment in reducing marine microplastics, J. Environ. Manage. 266 (2020) 110642, https://doi.org/10.1016/j.jenvman.2020.110642.

[94] S. Wolff, J. Kerpen, J. Prediger, L. Barkmann, L. Müller, Determination of the microplastics emission in the effluent of a municipal waste water treatment plant using Raman microspectroscopy, Water Res. X. 2 (2019) 100014, https://doi.org/ 10.1016/j.wroa.2018.100014.

[95] J. Talvitie, A. Mikola, O. Setälä, M. Heinonen, A. Koistinen, How well is microlitter purified from wastewater? - A detailed study on the stepwise remova of microlitter in a tertiary level wastewater treatment plant, Water Res. 109 (2017) 164-172, https://doi.org/10.1016/j.watres.2016.11.046.

[96] Q. Xu, Y. Gao, L. Xu, W. Shi, F. Wang, G.A. LeBlanc, S. Cui, L. An, K. Lei, Investigation of the microplastics profile in sludge from China's largest Water reclamation plant using a feasible isolation device, J. Hazard. Mater. 388 (2020), https://doi.org/10.1016/j.jhazmat.2020.122067.

97] F. Corradini, P. Meza, R. Eguiluz, F. Casado, E. Huerta-Lwanga, V. Geissen, Evidence of microplastic accumulation in agricultural soils from sewage sludge disposal, Sci. Total Environ. 671 (2019) 411-420, https://doi.org/10.1016/j. scitotenv.2019.03.368.
[98] P. van den Berg, E. Huerta-Lwanga, F. Corradini, V. Geissen, Sewage sludge application as a vehicle for microplastics in eastern Spanish agricultural soils, Environ. Pollut. 261 (2020) 114198, https://doi.org/10.1016/j. envpol.2020.114198.

99] L. Zhang, Y. Xie, J. Liu, S. Zhong, Y. Qian, P. Gao, An overlooked entry pathway of microplastics into agricultural soils from application of sludge-based fertilizers, Environ. Sci. Technol. 54 (2020) 4248-4255, https://doi.org/10.1021/acs. est.9b07905.

[100] P.A. Helm, Improving microplastics source apportionment: A role for microplastic morphology and taxonomy? Anal. Methods 9 (2017) 1328-1331, https://doi.org/ 10.1039/c7ay90016c.

[101] T. Wang, X. Zou, B. Li, Y. Yao, Z. Zang, Y. Li, W. Yu, W. Wang, Preliminary study of the source apportionment and diversity of microplastics: taking floating microplastics in the South China Sea as an example, Environ. Pollut. 245 (2019) 965-974, https://doi.org/10.1016/j.envpol.2018.10.110.

[102] A.E. Schwarz, T.N. Ligthart, E. Boukris, T. van Harmelen, Sources, transport, and accumulation of different types of plastic litter in aquatic environments: a review study, Mar. Pollut. Bull. 143 (2019) 92-100, https://doi.org/10.1016/j. marpolbul.2019.04.029.

[103] P. Kay, R. Hiscoe, I. Moberley, L. Bajic, N. McKenna, Wastewater treatment plants as a source of microplastics in river catchments, Environ. Sci. Pollut. Res. 25 (2018) 20264-20267, https://doi.org/10.1007/s11356-018-2070-7.

[104] L.K. Schmidt, M. Bochow, H.K. Imhof, S.E. Oswald, Multi-temporal surveys for microplastic particles enabled by a novel and fast application of SWIR imaging spectroscopy - study of an urban watercourse traversing the city of Berlin, Germany, Environ. Pollut. 239 (2018) 579-589, https://doi.org/10.1016/j. envpol.2018.03.097.

[105] S.H. Campbell, P.R. Williamson, B.D. Hall, Microplastics in the gastrointestinal tracts of fish and the water from an urban prairie creek, Facets 2 (2017) 395-409, https://doi.org/10.1139/facets-2017-0008.

[106] L.L. Hylton, J. Ghezzi, Microplastic pollution in Indiana's White River: an exploratory study, Proc. Indiana Acad. Sci. 127 (2017) 1-102. https://www.inw mc.net/wp-content/uploads/2019/01/pias-127-01-72-Lindsay-Hylton-et-al.pdf.

[107] A.K. Baldwin, S.R. Corsi, S.A. Mason, Plastic debris in 29 great lakes tributaries: relations to watershed attributes and hydrology, Environ. Sci. Technol. 50 (2016) 10377-10385, https://doi.org/10.1021/acs.est.6b02917.

[108] A.R. McCormick, T.J. Hoellein, M.G. London, J. Hittie, J.W. Scott, J.J. Kelly, Microplastic in surface waters of urban rivers: concentration, sources, and associated bacterial assemblages, Ecosphere 7 (2016), https://doi.org/10.1002/ ecs2.1556.

[109] S. Estahbanati, N.L. Fahrenfeld, Influence of wastewater treatment plant discharges on microplastic concentrations in surface water, Chemosphere 162 (2016) 277-284, https://doi.org/10.1016/j.chemosphere.2016.07.083.

[110] J.R. Peller, L. Eberhardt, R. Clark, C. Nelson, E. Kostelnik, C. Iceman, Tracking the distribution of microfiber pollution in a southern Lake Michigan watershed through the analysis of water, sediment and air, Environ. Sci. Process. Impacts 21 (2019) 1549-1559, https://doi.org/10.1039/c9em00193j.

[111] L. Lin, L.Z. Zuo, J.P. Peng, L.Q. Cai, L. Fok, Y. Yan, H.X. Li, X.R. Xu, Occurrence and distribution of microplastics in an urban river: a case study in the Pearl River along Guangzhou City, China, Sci. Total Environ. 644 (2018) 375-381, https:// doi.org/10.1016/j.scitotenv.2018.06.327.

[112] J.C. Vermaire, C. Pomeroy, S.M. Herczegh, O. Haggart, M. Murphy, Microplastic abundance and distribution in the open water and sediment of the Ottawa River, Canada, and its tributaries, Facets 2 (2017) 301-314, https://doi.org/10.1139/ facets-2016-0070.

[113] R. Dris, J. Gasperi, B. Bounoua, V. Rocher, B. Tassin, Microplastics in different compartments of the Urban Water cycle: from the sources to the Rivers. Fate Impact Microplastics Mar. Ecosyst., 2017, pp. 7-8, https://doi.org/10.1016/ b978-0-12-812271-6.00007-7.

[114] H.A. Leslie, S.H. Brandsma, M.J.M. van Velzen, A.D. Vethaak, Microplastics en route: field measurements in the Dutch river delta and Amsterdam canals, wastewater treatment plants, North Sea sediments and biota, Environ. Int. 101 (2017) 133-142, https://doi.org/10.1016/j.envint.2017.01.018.

[115] Z.L.R. Botterell, N. Beaumont, T. Dorrington, M. Steinke, R.C. Thompson, P. K. Lindeque, Bioavailability and effects of microplastics on marine zooplankton: a review, Environ. Pollut. 245 (2019) 98-110, https://doi.org/10.1016/j. envpol.2018.10.065

[116] W. Wang, J. Ge, X. Yu, Bioavailability and toxicity of microplastics to fish species: a review, Ecotoxicol. Environ. Saf. 189 (2020) 109913, https://doi.org/10.1016/ j.ecoenv.2019.109913.

[117] E. Uurasjärvi, S. Hartikainen, O. Setälä, M. Lehtiniemi, A. Koistinen, Microplastic concentrations, size distribution, and polymer types in the surface waters of a northern European lake, Water Environ. Res. 92 (2020) 149-156, https://doi. org/10.1002/wer.1229.

[118] J. Marsalek, B. Jiménez-Cisneros, P.-A. Malmquist, M. Karamouz, J. Goldenfum, B. Chocat, Urban water cycle processes and interactions, Urban Water Cycle Process. Interact. (2014), https://doi.org/10.1201/9781482288544.

[119] L. Daana, K. Kanhai, C. Johansson, J.P.G.L. Frias, K. Gardfeldt, R.C. Thompson, I. O. Connor, Deep-Sea research part I deep sea sediments of the Arctic Central Basin : a potential sink for microplastics, Deep. Res. Part I. 145 (2019) 137-142, https://doi.org/10.1016/j.dsr.2019.03.003.

[120] M. Kooi, A.A. Koelmans, Simplifying microplastic via continuous probability distributions for size, shape,and density, Environ. Sci. Technol. Lett. 6 (2019) 551-557, https://doi.org/10.1021/acs.estlett.9b00379. 